
CENSUS:

\title{
DISCUSSION AND RECOMMENDATIONS
}

Date Published - September 1990

\author{
BRUCE TONN \\ ROBERT EDWARDS \\ RICHARD GOELTZ \\ KERRY HAKE
}

\section{RESEARCH SPONSORED BY THE 21ST CENTURY STAFF OF THE U.S. BUREAU OF THE CENSUS UNDER INTERAGENCY AGREEMENT NO. 1941-B(\%)3-AI}

Prepared by the

Oak Ridge National Laboratory

Oak Ridge, Tennessec 37831 operated by

Martin Marictta Energy Systems, Inc.

for the

U.S. DEPARTMENT OF ENERGY

under Contract No. DE-ACOS-840R2140()

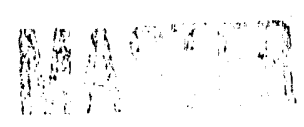


TABLE OF CONTENTS

EXECUTIVE SUMMARY $\ldots \ldots \ldots \ldots \ldots \ldots \ldots \ldots \ldots \ldots \ldots \ldots \ldots$

1.0 INTRODUCTION $\ldots \ldots \ldots \ldots \ldots \ldots \ldots \ldots \ldots \ldots \ldots \ldots \ldots \ldots$

2.0 TECHNOLOGY MANAGEMENT LITERATURE $\ldots \ldots \ldots \ldots \ldots \ldots \ldots \ldots \ldots$

2.1 PRIVATE SECTOR ISSUES $\ldots \ldots \ldots \ldots \ldots \ldots \ldots \ldots \ldots \ldots \ldots \ldots$

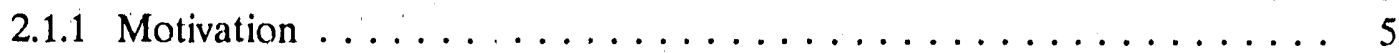

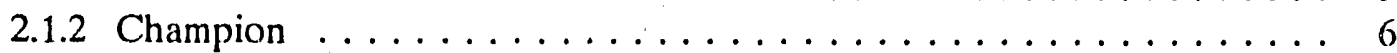

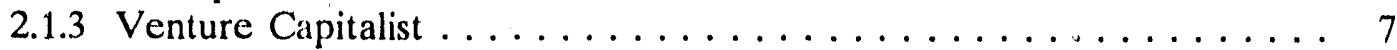

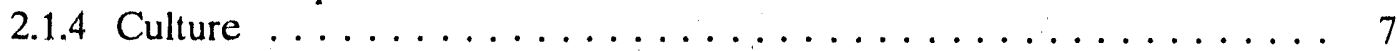

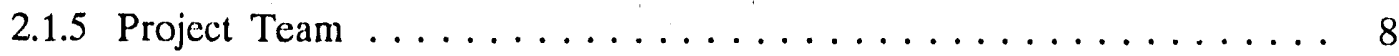

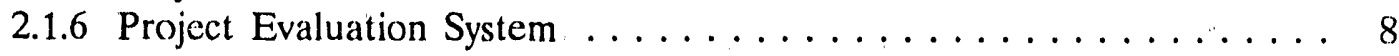

2.1 .7 New Venture Unit $\ldots \ldots \ldots \ldots \ldots \ldots \ldots \ldots \ldots$

2.1 .8 Chief Technology Officer $\ldots \ldots \ldots \ldots \ldots \ldots \ldots \ldots \ldots \ldots$

2.1 .9 Sociotechnical State $\ldots \ldots \ldots \ldots \ldots \ldots \ldots \ldots$

2.2 TECHNOLOGY MANAGEMENT IN THE PUBLIC SECTOR $\ldots \ldots \ldots \ldots$

2.3 RESOLUTION OF TECHNOLOGY ISSUES IN THE PUBLIC SECTOR . . 14

3.0 TECHNOLOGY AND THE CENSUS . . . . . . . . . . . . . . . . . . . 19

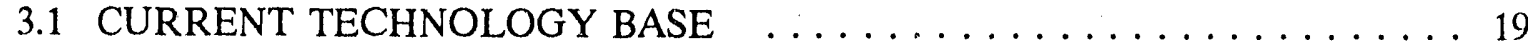

3.2 EVALUATION OF CENSUS BUREAU INNOVATIONS $\ldots \ldots \ldots \ldots \ldots \ldots$

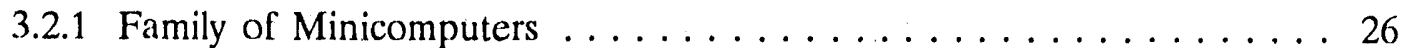

3.2 .2 TIGER . . . . . . . . . . . . . . . . . . . . . . 27

3.2.3 Computer Assisted Telephone Interviewing . . . . . . . . . . . . . 29

3.2 .4 CD-ROM .......................... 29

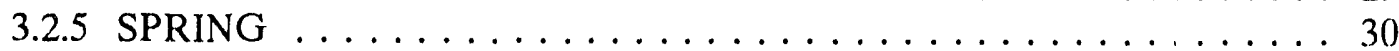

3.2.6 FOSDIC and Optical Mark Recognition . . . . . . . . . . 30

3.2 .7 General Observations . . . . . . . . . . . . . . . 31

3.3 SUMMARY OF INTERVIEW COMMENTS $\ldots \ldots \ldots \ldots \ldots \ldots \ldots \ldots \ldots$

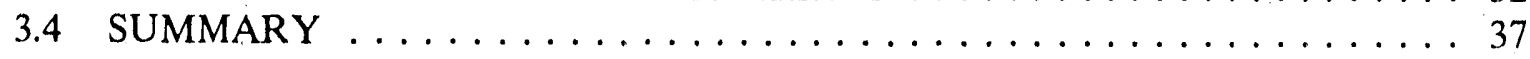

4.0 RECOMMENDATIONS ... . . . . . . . . . . . . . . . . . 39

4.1 THE TECHNOLOGY FORUM $\ldots \ldots \ldots \ldots \ldots \ldots \ldots \ldots \ldots \ldots \ldots$

4.2 TECHNOLOGY REVIEW COMMITTEE ................ 46

4.3 TECHNOLOGY GURUS . . . . . . . . . . . . . . . . . . . . . . 49

4.4 PROCESS FOR TECHNOLOGICAL INNOVATION . . . . . . . . . . . 50

4.5 ADVANCED TECHNOLOGY STUDIES STAFF . . . . . . . . . . . . 54

5.0 SUMMARY AND DISCUSSION $\ldots \ldots \ldots \ldots \ldots \ldots \ldots \ldots \ldots \ldots \ldots$

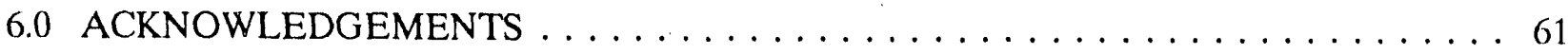




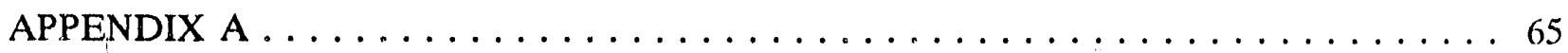

A.1 COMMENTS ON REPORT AND RECOMMENDATIONS

IN GENERAL ............................. 65

A.2 COMMON MISCONCEPTIONS ABOUT THE RECOMMENDATIONS . . . 67

A.3 COMMENTS ON THE TECHNOLOGY FORUM RECOMMENDATION . . 68

A.4 COMMENTS ON THE TECHNOLOGY REVIEW COMMITTEE RECOMMENDATION . . . . . . . . . . . . . . . . . 69

A.5 COMMENTS ON THE TECHNOLOGY GURUS RECOMMENDATION ...................... 71

A.6 COMMENTS ON THE TECHNOLOGICAL INNOVATION PROCESS

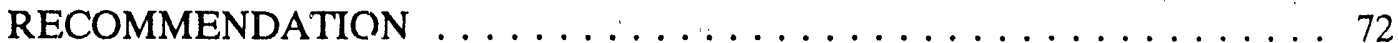

A.7 COMMENTS ON THE ADVANCED TECHNOLOGY STUDIES STAFF

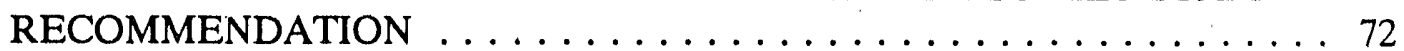

A.8 MULITPLE RECOMMENDATION COMMENTS $\ldots \ldots \ldots \ldots \ldots \ldots 75$

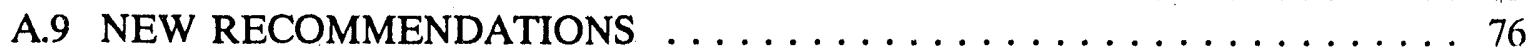

A.10 OBSERVATIONS AND IMPLEMENTATION RECOMMENDATIONS $\ldots .76$ 


\section{LIST OF TABLES}

Table 1. Factors Affecting Census Bureau Innovations $\ldots \ldots \ldots \ldots \ldots$

Table 2. Relationship of Recommendations to Bureau

Technology Innovation and Management Issues . . . . . . . . . . . 47 


\section{EXECUTIVE SUMMARY}

This report contains a set of recommendations prepared by Oak Ridge National Laboratory (ORNL) for the 21st Century Staff of the U.S. Bureau of the Census pertaining to technology innovation and management in the Census Bureau. The topic is extremely importint because technology has the potential to benefit the Bureau's data collection, capture, processing, and analysis activities. However, these benefits will be received only if new technologies are well conceived and managed.

A major activity of this project was to interview Census Bureau staff about technology innovation and management in the Bureau. The interviews helped sharpen issues and potential recommendations. More than 40 people took part in the project. The entire Burcau was represented from Decennial Census to Economic Prograns. Also represented in the sample are various levels of Bureau management and numerous experts in technology.

Technology is normally thought of as a private sector concern; for example, most technology management literature pertains to the private sector. In business, competition fuels innovation, which is facilitated by technology champions, funding patrons, and organizations primed for technological change. The public sector can implement most private sector technology management techniques, but must find ways to replicate the urgency of competition to spark innovation in its own organizations and to overcome the extraordinary difficultics of funding and procurement.

During the 1980s, the Census Bureau has witnessed a great deal of technological change. The 1990 Decennial Census operations plan incorporates for the first time a family of minicomputers. Throughout the Burcau, workstations, minicomputers, and microcomputers have found their place along side the Bureau's mainframes. The Bureau's new computer tile structure called the Topologically Integrated Geographic Encoding and Referencing data base (TIGER) represents a major innovation in geographic information systems and impressive progress has been made with Computer Assisted Telephone Interviewing (CATI). Other innovations, such as SPRING, which aims to provide Bureau demographic analysts with the capability of interactive data analysis on minicomputers, are in the initial stages of development.

The innovation and technology management process has required much effort on the part of Census Bureau staff. This is because several factors act to restrict technology change. These factors include the restrictive procurement process, uncertainty about the amount and timeliness of funding for innovations, and how to manage centralization and decentralization of the Burcau's technology. The interviews also suggest that the Bureau needs to continue to evolve its innovation culture and leadership in the technology area.

Given that the Bureau has a recent history of innovative successes, our recommendations are designed to complement and fine tune valuable existing Burcau processes and combat those problems that work against technology change and innovation. The Bureau can implement each recommendation itself (i.e., no recommendation depends on the Bureau changing government procurement recommendations or personnel systems, for example). Recommendations fall into five independent, but mutually beneficial categories. 
First, it is recommended that the ADP Steering Committee be disbanded and replaced with 'The Technology Forum. The Bureau should assign it the responsibility of debating and discussing a troad range of technologies. The Forum should be a place to discuss technology issues that cut across organizational boundaries. It is expected that the Fnrum will present to the Executive Staff f sr approval major technological policy proposals. In turn, the Forum will have the responsibility ior technical decisions about implementing technological policy. It is recommended that somenne representing an operations division head the Forum.

A second recommendation pertains to the establishment of a Technology Review Committee (TRC), to be composed of technology experts from outside the Bureau. The TRC will help motivate the Bureau to continue to adopt new technologies and will provide a regular flow of critical comments on technology innovation and management to the Bureau's Executive Staff.

A third recommendation encourages the Bureau to designate technological gurus. These individuals will be the Bureau's experts in new and innovative technologies. The Forum, for example, could approve recommendations on the status of "technological gurus" within the Bureau. These individuals will receive time and some additional financial support to facilitate their staying on top of an important technological field. In return, the gurus will be available to all divisions in the Bureau for consultation.

Fourth, it is recommended that the Bureau adopt a technology innovation process. The process indicates the roles of and interactions between technology champions and gurus, venture capitalists, organizations reviewing project progress, and people whose responsibility it is to implement the new technology in Bureau operations. Recognizing that a common innovation process will help promote innovation in the Bureau. Keeping the process relatively informal will provide the flexibility needed to develop new ideas.

Fifth, it is recommended that the Census Bureau establish an Advanced Technology Studies Staff (ATSS) to promote technology transfer, obtain funding for technological innovation, manage innovation projects unable to find a home in other divisions, evaluate innovations that cut across Bureau organizational boundaries, and provide input into Bureau technology analyses. The staff should be headed by a technically knowledgable individual who is cognizant of the workings of the entire Bureau. The balance of the staff should possess technical and analytical backgrounds and could be a mix of permanent staff and staff on loan from other divisions. It is recommended that the ATSS report directly to the Director/Deputy Director of the Bureau, possibly as part of a reconceptualized 21st Century Staff.

In summary, these recommendations are designed to enhance the Bureau's current innovation processes, which already has several successes to its credit. The recommendations can be adopted and implemented separately or all together. Each is doable, not only because none represent a radical departure from the present state of affairs, but also because none depends on the Bureau changing its external environment. 
A draft of this report was circulated for review. Comments on the recommendations are presented and addressed in Appendix A. None of the comments possess the persuasive weight needed to alter the above recommendations. As suggested, a small group of Census Bureau senior managers should be appointed to study the recommendations and report their findings to the executive staff. 


\section{"Technology has revitalized the Census Bureau." \\ Census Bureau Manager, Summer 1989}

\subsection{INTRODUCTION}

This report is about technology and the U.S. Bureau of the Census. The topic is timely hecause technology is viewed by the Bureau and many other federal agencies as possibly THE most important means by which to accomplish their missions in an increasingly complex and demanding environment. With respect to the Bureau, its environment is characterized by: a vocal and extremely diverse constituency interested in the quality and availability of Decennial Census data and other data products; ever tightening budgets; increasingly complex and burdensome procurement regulations; and a rapidly changing workforce, population and economy. The Bureau must collect, capture, process, disseminate, and analyze data for numerous surveys that vary in CONTENT, from household demographics to manufacturing data, PERIODICITY, from monthly to every ten years, and in SCALE, from a sample of a few thousand to the Decennial, which in 1990 will include over one hundred million housing units. Technology can help the Bureau accomplish its mission in any number of ways, but technology does noi just happen. It needs nurturing, funding, commitment, and organization; these ideas are central to technology innovation and management.

The terms "technology innovation and management" are intended to have very broad definitions. They should not conjure up visions of a highly cautious and expanding bureaucracy determined to closely manage every microcomputer and word processing package in a large organization. Instead, the terms should be understood to refer to organizational structure and processes which can: promote technological innovation and technology transfer; evaluate and lund new ideas; and coordinate technology change throughout an organization. One goal of technology 
management is to remove barriers thwarting beneficial technological change, while maintaining evaluation processes to weed out less valuable ideas. Good technology management will result in cost avoidance, better data, and enhanced jobs within an organization like the Census Bureau.

The 21st Century Staff (TCS) of the U.S Census Bureau tasked Oak Ridge National Laboratory (ORNL) with examining technology innovation and management in the Census Bureau. At the direction of the TCS, technology was defined as including any hardware, computer or otherwise, and advanced software that could be used by the Bureau in its daily operations. This project is important to the Census Bureau because it needs to conduct advanced planning for the Year 2000 census, and technology should play a major role in this effort. Recommendations generated by this project are designed to improve the Bureau's Decennial Census planning process and allow the Bureau to capitalize on new technologies for use throughout the agency.

ORNL approached this task in three ways. First, two ORNL two-person teams interviewed more than 40 Bureau staff to gather facts on recent Bureau technological innovation and elicit opinions on Bureau technology innovation and management. Interviewees were chosen for their knowledge of Bureau technology and their ability to influence technological decisions. Also, interviewees were chosen to represent the work and viewpoints of the entire Bureau. Interviews with senior management lasted approximately one hour; those with technical staff approximately two hours.

Second, ORNL conducted a thorough literature review on the topics of technology innovation and management. Much has been written on these topics with respect to technology management in the private sector and technology transfer from the putlic sector to the private sector. Because this report addresses technology management in the public sector and technology transfer from the private to the public sector, the literature only provided a foundation with which 


\section{$3 / 4$}

to assess technology innovation and management in the Bureau. However, the new ideas and approaches to public sector technology contained in this report benefitted from this theoretical foundation.

Third, ORNL coalesced information described above into a set of recommendations designed to enhance technology innovation and management in the Bureau.

The next section of this report summarizes the literature on technology management. Because this literature mostly deals with the private sector, the second part of Sect. 2.0 contrasts these findings to the realities of the public sector. Section 2.3 presents general solutions to special technology related problems that arise in the public sector. Section 3.0 discusses the Bureau's current technology base, which has impressively evolved during the 1980s. The model developed in Sect. 2.0 is used to evaluate those factors that had an important effect on innovation in the Bureau. Section 3.0 concludes with a presentation of technology management issues found important to Bureau staff. Section 4.0 presents recommendations for technology innovation and management in the Bureau. The recommendations address how to allocate technology management responsibilities within the Bureau, the formation of a technology advisory committee, a sugrgested process for technological innovation, and the formation of a staff for advanced technology studies. Section 5.0 presents comments made by Census Bureau staff and others on the recommendations. Also presented are ORNL responses to the comments. 


\subsection{TECHNOLOGY MANAGEMENT LITERATURE REVIEW}

\subsection{PRIVATE SECTOR ISSUES}

Let's begin by debunking a myth, that "technology" represents a miracle, a rare and unique achievement of the human mind. Literature on technology innovation in the private sector does not support this myth. In fact, companies rarcly suffer a shortage of ideas for new technology either to be developed in-house or imported from the outside. The problem is trying to sell new ideas whose costs and benefits are largely uncertain. The miracle is that any new idea is able to survive the questioning process generated by people in the companies themselves and by people in the larger socioeconomic environment.

In a very rea' sense, then, technology is a people problem. Any new idea can be challenged and thwarted at any time, be it related to a radical technological change or to a small, seemingly inconsequential technological change. For this reason, any change in the technological base of an organization can be considered an innovation. Managing innovation, therefore, is extremely important and basically consists of selling new ideas to various key people at various levels of the organization. The objective details of technology innovation and management may be complicated but the real challenge is having the intestinal fortitude required to handle the subjective aspects of the process.

\subsubsection{Motivation}

Fortunately, the literature does contain pieces of advice that one can combine with eternal optimism and unlimited persistence to achieve technological change in large organizations. First, a MOTIVATION is required. The most important motivation pushing innovation in the private sector is competition, be it real or imagined (Pearson, 1988). Competition of any kind can spur 
innovation. For example, in response to competition from countries with low labor costs, U.S. companies can continue to automate. In response to competition from countries with high levels of technological sophistication, U.S. companies can try to match and surpass other countries' technology to increase product and service quality and productivity, and to develop new products. Sectors of the economy such as computers, finance, and consumer electronics are characterized by a high level of technological change, but sectors as diverse as agriculture, automotives and stecl are also actively pursuing new technologies.

One could hypothesize other private sector motives for technological innovation but, in all likelihood, each could be tied to making profits in a compctitive world. As discussed in Sect. 2.2, motivations related to job quality and performance not tied to profit making may be more important factors spurring innovation in the public sector than in the private sector.

\subsubsection{Champion}

It is a rare industry that is not interested in technological innovation. Besides motivation, however, three other factors are necessary to foster innovation. One is the need for a CHAMPION, whose major responsibility is having "The Vision." As mentioned in the introduction, technology doesn't just happen. An idea can be generated by an individual or a group, but someone must be its advocate, from the beginning of the project to the end. That someone must have the intestinal fortitude to obtain funding and resources in the face of naysayers and stifling bureaucratic barriers, be they within the company or part of government. Without a champion, there is little chance for a new technology to succeed. 


\subsubsection{Venture Capitalist}

A third necessary factor is a VENTURE CAPITALIST (or as Pearson, 1988, would say, a 'sugar daddy'). In addition to the champion, someone who has discretion over financial resources must be willing to fund the innovation. Chacko (1988) found that instances of innovation success are characterized by "the unequivocal commitment of substantial resources to products and/or processes when they were largely a technological gleam in the eye (p. 88)." He gives as an example of success in the public sector the Manhattan Project, which received $\$ 2.19$ billion in funding over its first fours years. For comparison purposes, the 1940 combined Army and Navy appropriation was $\$ 1.18$ billion. In contrast, German scientists were never able to receive a commitment from the Nazi government for development of an atomic bomb.

\subsubsection{Culture}

A fourth necessary factor in fosiering technological innovation is the organization's CULTURE. The organization must have processes in place to reward risk taking even if a new idea is discarded after the expenditure of substantial resources (Crescenzi, 1988). The organization must expect technological change. For example, a company could expect as a matter of course that, say, five years into the future, half of its revenue will come from products yet to be invented (Chacko 1988). An organization also must whole-heartedly embrace the idea that it is not the only source of new technological ideas. The "not invented here syndrome" is a cultural trait which seriously limits valuable innovation (Steele, 1989). Formal contacts with innovative organizations and frequent informal contacts at conferences and workshops are suggested to overcome this cultural problem. 


\subsubsection{Project Team}

Having the motivation, a champion, a venture capitalist, and a willing organizational culture are prerequisites for innovation and technological change, but they are not the only factors important in the entire process. Once a champion has been found or has coine forward, and once funding has been budgeted, the next step is putting together a PROJECT TEAM. The team needs the proper technical skills and people who will feel comfortable with the champion. According to Crescenzi (1988), the team must not be too large--6 to 8 members for prototype work--and must exhibit an unselfish, all-for-one style. This is because the pace of work on innovations, especially on new products, is often hectic and if the project is to be successful, it must be accepted up front that it will not be possible to go back and evaluate who should get what credit for the project.

\subsubsection{Project Evaluation System}

Of benefit to the organization, but probably of consternation to the project team, is a good PROJECT EVALUATION SYSTEM. At every stage in the process, from original idea to full implementation, the organization must be able to evaluate the benefits and costs of a new technology. Gold (1988) states that many common errors are made in project evaluations. Here are eight.

1) The time needed to utilize a new technology is underestimated.

2) Use of a new technology is overestimated.

3) The evaluation criteria are too narrow and sometimes too quantitative. Shlany times the ripple effects--good and bad--of a new technology are not thought through.

4) Hardware issues are overemphasized relative to staff support issues.

5) Labor acceptance of a new technology is often neglected.

6) Wage cost reductions are overestimated because some labor will shift from unskilled to highly skilled categories. 
7) The people who originated the project often develop the evaluation numbers, which then may be biased. Specifically, Gold states that "since evaluations should be objective and evaluators should be technically capable, this responsibility may have to be assigned to some senior official (p. 25)."

8) New uses for a technology, especially for information systems, are often neglected.

These ideas should be kept in mind in the technology evaluation process. However, to help the organization learn how to conduct better evaluations, Gold (1988) stresses the importance of doing post implementation evaluations to highlight mistakes made in the preevaluation.

\subsubsection{New Venture Unit}

The last three issues pertain to the organizational structure within which technology innovation and management take place. The first issue is related to where in the organization the project team will reside. Numerous organizations have found that operational divisions cannot or will not take responsibility for managing innovation project teams. Often, the stresses of day-to-day operations preclude working on "luxury" projects. Sometimes, the operating environment may be too hostile to allow an innovation project. For example, some managers may fear the loss of responsibility if the project succeeds; technical staff may develop professional jealousies for the same reason. In such cases, and only in such cases according to Bart (1988), the organization should consider establishing a NEW VENTURE UNIT outside of the operating divisions to work on innovations. If this is done, special attention must be made to transferring the technology from the new venture unit back to the operating division, primarily by involving key members of the operating division in-progress reviews of the innovation (Leonard-Barton 1987). 


\subsubsection{Chief Technology Officer}

A second organizational issue relates to leadership. In addition to a champion and a venture capitalist, the organization may consider the appointment of a CHIEF TECHNOLOGY OFFICER (CTO), who reports directly to the chief executive officer (Donovan 1988). This person must have a broad understanding of the entire organization, not just a narrow expertise in technology. The CTO should be able to see benefits of technology that cut across the orgenization and should have the responsibility to actually help remove the myriad of organizational barriers that work against innovation and effective technology management. For example, the CTO might make the recommendation to establish a new venture unit but would not run the unit, per se. This person might also double as the venture capitalist. Lastly, the CTO would act to overcome any problems inherent in the organization's decision processes that delay or stifle decisions about new technology.

\subsubsection{Sociotechnical State}

The CTO would also be concerned with the third issue, that of appraising the organization's SOCIOTECHNICAL STATE of being, in order to establish the optimal strategic approach to technology change in the organization (Chisholm 1988). For example, it is not a good idea to adopt a new technology and then force employees to use it. Instead, the process is more holistic, dynamic and incremental, with employees being introduced to a new idea at the beginning of the process and informed of technological progress at each step of the innovation process. Employee suggestions should be considered and incorporated as appropriate at every step in the process. A CTO may be needed to ensure that everyone has access to decisions regarding new technology and 
to provide input to the $\mathrm{CEC}$ and/or a board of directors to help resolve conflicts of opinion regarding technological issues.

The sociotechnical state of the organization has a flip side, too, pertaining to noncultural barriers to technological change. For example, there may be laws and/or governmental regulations which may restrict the introduction and/or procurement of certain new technologies. Also, the organization's product and/or mission may have special characteristics that constrain when and how technology decisions are made. There is no better example of this than the Bureau's mission to conduct the Decennial Census, which demands long lead times for technology planning development and acquisition. Lastly, the current sociotechnological base may be so rigid and inflexible that it might be better to shut down an entire operation and start over from scratch, even though this may rarely be possible in the public sector.

To summarize, the literature on technology innovation and management provides nine ideas or concepts useful to study these issues for the Census Bureau. These ideas are motivation, champion, venture capitalist, culture, project team, project evaluation system, new venture unit, chief technology officer, and sociotechnical state. As a set, the ideas loosely compose a theory and in this report we shall refer to the set of ideas as a theory of technology innovation and management. This is useful because we can then assess the value of the theory with respect to public sector organizations, as is done in Sect. 2.2. We can also use the theory to evaluate which parts seem more important to the Bureau, which is accomplished in Sect. 3.0. Lastly, the theory provides the foundation with which to map Bureau technology innovation and management needs onto the recommendations presented in Sect. 4.0. 


\subsection{TECHNOLOGY MANAGEMENT' IN THE PUBLIC SECTOR}

Many of the ideas related to technology innovation and management in the private sector have relevance to the public sector. For example, there is no reason to assume that champions for new technologies cannot be found in public sector organizations. Indeed, our discussions with Census Bureau staff highlighted several champions (see Sect. 3.2). Also, there should be no barriers preventing public organizations from establishing formal contacts with innovative organizations, developing a technological infrastructure, appointing a chief technology officer, establishing procedures for evaluating new technologies, and rewarding innovators. Thus, at the very least, public and private organizations should be able to manage technology equally well.

On the other hand, major differences exist between private and public sector organizations with respect to innovation. The biggest difference is COMPETITION. Profit-Making competition drives innovation in the private sector and is absent in the public sector. Are there other forms of competition that could drive the public sector to innovate? What arguments can a champion use to justify an organization's investment in a new technology and his or her undertaking a most difficult, frustrating, and possibly career-threatening exercise? What should drive the Census Bureau to innovate?

Another difference between the private and public sectors is that it is particularly DIFFICULT TO QUANTIFY THE BENEFITS to public organizations of technological innovations. This is an important problem because investments on risky projects will not be made unless persuasive (i.e., quantitative) arguments can be made on behalf of innovations. Usually in the private sector, the arguments center on profit, market share, and corporate growth, which are relatively easy to measure although notoriously difficult to forecast. The point is that discussions 
about new technologies will be more productive if the participants at least have a common understanding of the goals of the organization and measures of success.

Unfortunately, there are no universally agreed on criteria with which to indicate the success of public organizations, irregardless of their technological base. The Census Bureau lacks formal systematic empirical and quantified assessments of value of data products and mission to current and future taxpayers. This causes difficulty in measuring organizational success. Fourth, with no rigorously quantifiable means of valuing its activities, the Bureau cannot gauge the worth of new technology to those activities, at least independently of the political process.

In fact, there are no easily definable criteria with which to evaluate projects. It may seem simple to evaluate how much the Bureau spends or might spend to collect and analyze data with and without new technologies. However, expenditures depend on meeting deadlines, maintaining data quality and on other often subjective criteria, which are difficult to value and measure. Thus, it becomes difficult to state definitively whether the Bureau has done all it could or can do to meet its mission in the most cost-effective manner. This problem needs some resolution in order to improve technology decisions in the Bureau and more generally in the public sector.

Another particularly daunting problem for public organizations is MAINTAINING MOMENTUM. In the private sector, it helps the champion and the organization that funding decisions can be made quickly, and that equipment and staff can be easily obtained. In the public sector, budget cycles and the budgeting process may work against the innovation process because money may not be available when needed. For example, a federal organization may have to wait two or more years to get funding for a major technological innovation into the budget process and then hope that the funds are not cut during Congressional and intra-organization dobates. Even 
if the funds hecome available, the procurement process could further the delay of a project. Only the most determined champions and organizations can manage to survive these delays.

Finally, public sector organizations may have difficulty in putting together a PROJECT TEAM. First, the requisite technical experience may not be available in the organization. Indeed, most public organizations are not involved in developing technology, at least not in ways similar to a private high-tech company, so they would not necessarily be expected to have such employees. Hiring people for a short term project may be particularly difficult given government pay rates and lack of career opportunities. The procurement issue raises its ugly head again if the public organization attempts to obtain help from the private sector. This is because it is difficult to place sole-source contracts, and the competitive bidding process can take years to complete.

In summary, there are important differences between the private and public sectors with respect to technology innovation. The public sector must make a special effort to overcome the lack of competition and the barriers affecting project evaluation, momentum and project team building. Of course, any particular public sector organization may be afflicted with problems related to technology innovation and management, from a lack of champions and venture capital to rigid technology and a risk averse organizational culture.

\subsection{RESOLUTION OF TECHNOLOGY ISSUES IN THE PUBLIC SECTOR}

This subsection presents general ideas for resolving technology issues that particularly affect the public sector. These ideas will then be used in Sect. 4.0 to help formulate and defend recommendations related to technology innovation and management in the Census Bureau. With respect to COMPETITION, the key is to replicate the sense of urgency that accompanies the stimulus of competition. This can be done in a number of ways. For example, the public 
organization can convince itself that budget cuts, be they real or imagined, will absolutely prevent the organization from achieving its mission and that new technology is their only recourse. Although our discussions with Bureau staff indicate that they are prudently planning for worst case funding scenarios, it is debatable whether potential budget cuts motivate/enter into the technological picture in the Census Burcau. On one hand, the threat of budget cuts looms over every program in the federal government and some in the Bureau argue that the Bureau has already been affected. On the other hand, many of those interviewed in the Bureau believe that the Decennial Census in particular will receive whatever funding it needs.

Another argument centers on job quality and organizational health. Technologically trained people will not be attracted to work in a technologically moribund organization, especially a large one, which tends to generate stultifying rules and regulations as part of its nature. Public sector organizations may offer training and the promise of new technology but that may not be enough to retain their now more valuable staff. However, technology and the changes and challenges and opportunities inherent in technology can revitalize an organization, help retain valued staff, and help attract new employees. This beneficial viewpoint of technology is definitely alive and well in the Census Bureau.

A third approach is to create some competition. Maybe there are sister organizations within the federal government or in neighboring states or communities with which an organization can establish a friendly competition. Census Bureau staff mentioned that there is a sense that agencies compete for stature and resources. "Keeping up with the Jones" may not produce the same sense of urgency inherent in the first two, but it couldn't hurt. This idea does exist to some degree in the Census Bureau because many innovations are intended to help the Bureau "kecp-up" and "catch-up" (See Sect. 3.2). 
There are two components to our general approach to overcoming the problem of EVALUATING THE BENEFITS of new technologies to public sector organizations. One, the Bureau needs to establish a list of potential benefits of new technologies and a list of potential liabilities. The elements of the lists should not be too precise and should be relevant to any new project proposed by any division of the Bureau. The benefits and costs should be ranked, on a scale of 1 to 10 perhaps, by their importance. A committee could rank the elements collectively or individually, in which case the individual rankings could be averaged together.

Two, new technologies should be evaluated against the elements on the list, again on a scale of 1 to 10 . As mentioned in Sect 4.4, evaluations can be done at any stage of the innovation process. Numerous kinds of decision rules can be applied to help rank all potential new technologies and/or to decide each individual project independent of others. These two components combine to form what is referred to in the report as a FORMAL cost benefit evaluation process.

The key behind these suggestions is avoiding time consuming, undefensible quantitative analyses and time consuming, undefensible and potentially racking internal discussions. The uncertainties associated with new technologies make it virtually impossible to forecast with an extreme amount of accuracy their impacts on the Bureau. So why try to do the impossible and produce biases against new ideas in the process? It is also important to remember that rigorously valuing the benefits of new technologies is difficult even if their impacts can be forecast. The above ideas allow a great deal of latitude in assessing things of value to the organization and in evaluating the value of new technologies to the organization. This flexibility is important in promoting new technologies in public organizations. 


\section{$17 / 18$}

It is beyond the scope of the report to comment upon budget and procurement processes that tend to work against project momentum except to say that utterly determined and dedicated individuals and organizations can and do overcome these barriers and enjoy the fruits of technological innovation within their lifetimes.

With respect to TEAM BUILDING, public sector organizations can find resources quickly if they know where to look. For example, federal organizations have access to universities, national laboratories and special purpose federal laboratories, such as the National Institute of Standards and Technology. State and local public sector organizations hove access to community colleges and philanthropic companies. Also, more government agencies are letting basic ordering agreement contracts, which essentially places the winning company on call, pending a task order from the agency. These kinds of contracts can be valuable if the agency is able to pick a well-qualilied firm, not simply the low bidder. Lastly, government can and does attract highly technically qualificd individuals in spite of the wage differential with the private sector if the challenges are rewarding and the organization is supportive. These and other issues are addressed by the recommendations presented in Sect. 4.0. 


\subsection{TECHNOLOGY AND THE CENSUS BUREAU}

This section has three parts. The first describes the Bureau's current technology base and is designed to provide insights into the Bureau's technology needs. Section 3.2 discusses several Bureau innovations with respect to the theory of technology innovation and management introduced in the previous section. Section 3.3 categorizes comments elicited from the interviews by their relationship to each aspect of the theory. This exercise indicates which areas of Bureau technology innovation and management are of most concern to the staff.

\subsection{CURRENT TECHNOLOGY BASE}

The discussion focuses separately on computer technology, telecommunication networks, data capture technology, and data product technology. The organization chart of the Bureau shown in Fig. 1 is provided for reference purposes. It is shown below that most areas of the Bureau have pursued technology innovation during the 1980 s.

In step with the rest of American society, the Bureau's computer technology evolved considerably in the 1980 s. In the beginning of the decade, the Bureau relied solely or. UNISYS (formerly UNIVAC) mainframes to process the Decennial Census data and data collected as part of the other Bureau surveys. Computers were not significantly used to help the Bureau's Field Division collect the 1980 Decennial Census data. Now, new computer technology is being employed in all Bureau operations.

For example, to help accomplish the 1990 Decennial Census, each of the approximately 450 Field Division's District Offices has a Digital Equipment Corporation Microvax to assist the management of personnel and field work. These computers will also help manage the complex 


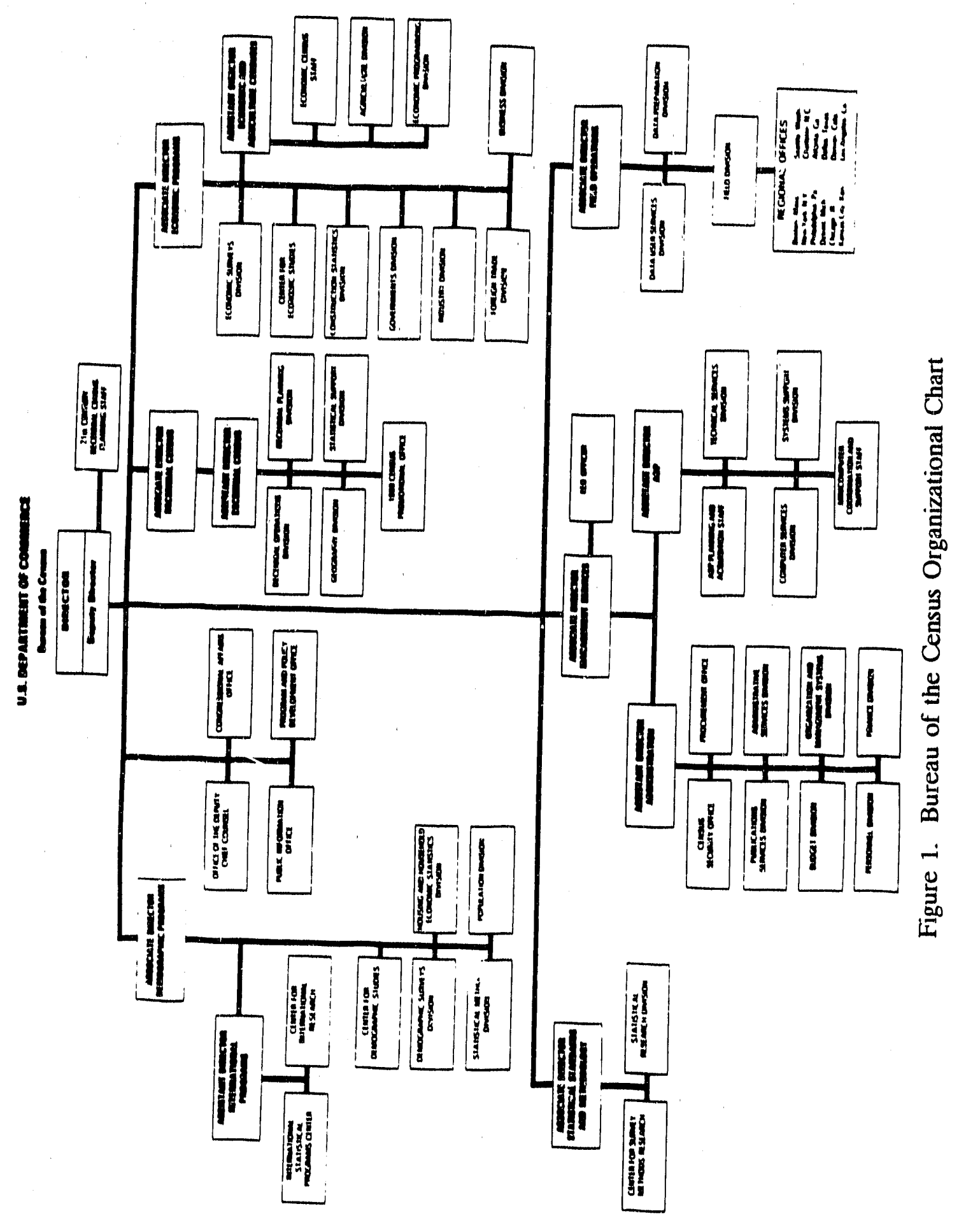


process of organizing approximately 300,000 newly hired enumerators, who will make sure that every household and special place has completed a Decennial questionnaire(s). VAX computers are located in each of the seven Processing Offices managed by the Decennial Operations Division and are designed, among many applications, to handle direct data entry of answers to opened-ended questions on the Decennial census forms (e.g., occupation and industry answers).

The Bureau's decision to utilize VAX technology evolved over a number of years. In fact, the Bureau had originally developed procurement specifications for only a small number of minicomputers. As the need for this kind of technology became apparent to the planners of the 1990 Decennial Census, the procurement grew into an $\$ 80$ million cortract, won by Digital Equipment Corp. The Bureau refers to this as the "Family of Minicomputers" contract. At the same time the 1990 Decennial Census operations were adopting new computer technologics, microcomputers, word processors and workstations were being acquired to support other Bureau operations. Preferences for these new technologies differ by Directorate and Division. For example, the Economic and Agricultural Censuses Divisions are developing all their operations around VAX technology, whereas the Demographic Programs area is working towards a networked workstation environment. This latter area is also seriously working to move some data processing and analysis operations off of the UNISYS mainframes and onto interactive machines. This project is known as SPRING (Butz 1989).

The infusion of new computer technologies into the Bureau has been accompanied by a decentralization of responsibility for the technology. Early in the 1980s, all responsibility for the UNISYS machines was located in the Management Services Directorate. This directorate still has responsibility for the UNISYS machines but much responsibility for the other computc: technologies now resides in the user divisions. 
This decentralization is particularly evident with respect to software development. In general, each division is now responsible for its own programming, including programming for the UNISYS machines. Several Bureau staff stated that this has spurred innovation in software, especially within the Decennial Operations and Field Divisions. The Bureau's software inventory includes programs written in FORTRAN, SAS, and C, as well as in many other languages. Recently, staff reporting to the Assistant Director for ADP has begun to generate programs using Computer-Assisted Software Engineering (CASE) tools.

The 1980 s witnessed several major innovations in computer systems at the Bureau in addition to the family of VAX computers described above. The most visable innovation to those outside of the Bureau may well be the Geography Division's digital cartography project, the Topologically Integrated Geugraphic Encoding and Referencing (TIGER) System. Developed as a tool to assist the individual enumerator, the system can automatically and dynamically produce multi-scale maps. It will provide maps for more than 300,000 separate enumerator assignment areas to assist in checking addresses, interview scheduling, and other field tasks as well as larger scale maps for a variety of uses (Marx 1988).

The TIGER project was a massive data synthesis, technology integration, and interagency cooperative venture. It involved the upgrading of existing digital cartographic information from the Bureau's GBF/DIME Files and selective incorporation of four digital thematic data 'layers' from the US Geological Survey 1:100,000 scaleDigital Line Graph map files. Algorithms and software were written on several computers for the data capture, geographic rectification, graphical preview and editing, and plotter output. The spatially oriented database structure and topology will provide a robust data platform for geographical analysis. Evidence for this is seen in the private sector, 
where Geographic Information Systems vendors are advertising their ability to interface with TIGER Files.

The Field Division has also made strides with its Computer Assisted Telephone Interview System (CATI). Currently, the CATI system is located at the Bureau's Hagerstown, MD site. It resides on a VAX minicomputer and is accessed by telephone interviewers interactively through individual terminals. CATI leads interviewers through an interview session, presenting each question on the screen for the interviewer to read. Answers from the respondent are directly input by the interviewer into CATI from the keyboard. The Bureau is finding that CATI helps to standardize the interview process, and allows better management of survey data, especially in longitudinal surveys. CATI data are also immediately available for analysis and, in the future, for automatic coding of opened-ended questions and automatic and on-line editing.

In addition to the computer technology, the Bureau has installed telecommunications technology. The advent of personal computers and workstations at the Bureau has ushered in the connectivity tool of Local Area Networks. There is no standard covering the use and proliferation of LANs and several varieties may be found at the Bureau. A standard for a Wide Area Network (WAN), however, does exist, developed by the Management Services organization.

The WAN has been established to connec $\imath$ all hosts, L.ANs, and shared peripherals, and provide a gateway to other networks. The standard is based on Ethernet (IEEE802.3). This backbone network topology will soon be centered on a ring formation linking hosts at Jeffersonville, Charlotte, and Suitland. State of the art equipment is used for bridging backbones, network routing, digital switching and bypassing, and high speed dedicated telecommunication lines.

An important part of the Bureau's operation is the capture of data from survey forms. Three technologies are currently being used for this purpose. The most conventional is key entry 
of all data into computers via interactive terminal systems. Data for open ended questions on 1990 Decennial Census forms will be captured in this way.

The Decennial Census organization also uses the two-part FACT90 microfilm system coupled with the FOSDIC automated mark detection system. The Economic Programs organization is working with an optical scanning system to store images of forms onto optical data disks combined with a sophisticated optical disk storage and retrieval machine.

The specialized technology of high speed microfilm recording of variable format paper forms, the FACT90 camera system, continues to function as the primary archival-quality data capture technology for the Decennial Census organization. Its high-speed, strobe-synchronized camera, in conjunction with the manipulator arms and vacuum suction table, can automatically advance, flatten, and image forms. The forms may be fed in either a continuous motion mode or stopped motion mode; stopped motion being where the pages of an individual multipage form are mechanically turned for separate imaging.

The FOSDIC mark detection equipment for the 1990 Decennial Census is a totally reconstructed technology. It is a digital version of what used to be a system based on analog circuit boards. It is able to identify and record the human-generated marks on the census forms as recorded by the FACT 90 on rolls of microfilm. Software on a desktop microcomputer has replaced much of the analog circuit boards making this generation of the FOSDIC an extremely flexible and fast data capture tool. Preliminary tests suggest that it will be able to 'read' and store in one minute the data from 1,100 pages recorded on microfilm.

The third data capture technology involves scanning and optical disk storage. This technology is undergoing testing for the Agricultural Census. Actual forms are individually placed into a scanning device, resembling a photocopier, which is able to capture the image. This image 
can be identified and classified either by an operator or by computerized recognition of the bar code on the form. Images are organized, recorded onto 12 inch laser disks, and stored in a jukebox-like retrieval device capable of holding 64 platters. Currently, the technology is being evaluated for use to archive data and for real-time analytical work.

The last technology to be discussed relates to the Bureau's need to distribute its data in forms accessible by the general public. Toward this end, the Data User Services Division has successfully initiated a computer tape production and distribution system and has inaugurated the use of Compact Disk Read Only Memory (CD-ROM) in addition to magnetic tapes and flexible diskettes. Some of the CD-ROMs currently available are the 1980 demographics by Zip Code and the 1985 housing core survey. Initial reception of the CD-ROM technology by data users has been excellent, and there are plans to produce more titles. Near-term releases include the city-county data book and the 1988 county business patterns. The Data User Services Division also provides microcomputer bulletin board services that provide data product information to the public, in addition to fielding over 4,000 phone calls every month.

In summary, the 1980s have seen the Bureau engage in numerous technological innovation projects. These include TIGER and CATI, the introduction of CD-ROM technology to distribute Census data and the major decision to utilize a family of minicomputers for the 1990 Decennial Census. New ideas such as SPRING are still in the initial stages of the innovation process. On the horizon, new innovations may incorporate artificial intelligence, supercomputers, parallel processors, optical image recognition, advanced e-mail products (e.g., groupware), on-line data facilities, satellite imaging, and fully automated district ofuces. Therefore, the Census Bureau has been doing many things right. 


\subsection{EVALUATION OF CENSUS BUREAU INNOVATIONS}

Covered in this subsection are six Bureau innovations that exist in some way, shape or form, and one new idea that failed. The technological innovations are listed down the left side of Table 1. They are evaluated with respect to the nine ideas related to innovation presented in Sect. 2.1, which are listed across the top of Table 1. Each innovation is discussed separately at first. Then, observations are made across the innovations to determine what seems to work in the Bureau.

\subsubsection{Family of Minicomputers}

As mentioned above, the Bureau entered into an $\$ 80,000,000$ agreement with Digital Equipment Corporation that provides the Bureau with a host of VAX minicomputers. The motivations behind the contract are job performance, especially in the District Offices, and job quality. Specifically, the Bureau was very interested in being able to easily port code across the entire range of computers. The interactive nature of the VAX machines will be a big improvement for data analysts over having to go through programmers to do batch work on the UNISYS mainframes.

The family of minicomputers never had a champion in the classic sense. That is, the champion who initiated discussions about VAX technology was replaced by numerous other individuals as time passed. Also, this project never had a venture capitalist in the classical sense, There never was a prototype phase, which also means there was never a project team and, obviously, no new venture unit. Instead, the Bureau asked for and received the money directly from Congress, bid the contract, awarded the contract, and then immediately started to integrate the technology into Bureau operations. 
The Bureau's cultural attitude toward the minicomputer acquisition could be described as "wanting to keep up with technology", especially interactive technology. There was no formal project evaluation, as defined in Sect. 2.3, although extensive discussions on the project encompassed people throughout the Bureau. The entire process benefitted from the presenee of a Chief Technology Officer-type out of the Management Services area and the fact the Bureau was ready and flexible enough to handle the new technology.

\subsubsection{TIGER}

The TIGER system is designed to enhance the performance and productivity of those involved in the 1990 decennial census. As of this writing, it has been in place for 18-24 months. It definitely has a champion in the Geography Division, but again, Congress acted as the venture capitalist. The TIGER System can be said to have a project team and a new venture unit if one agrees that practically the entire Geography Division of the Census Bureau meets the criteria for such a unit. The Bureau deliberately chose to be in the forefront with the TIGER technology. It was ready for the technology because of the need for a system to encompass the entire country and because of major problems in managing manual cartographic and photographic clerical updates associated with the GBF/DIME File technology developed for the 1980 census. No high-level manager has acted as a chief technology officer. Also, extensive analysis was conducted prior to the TIGER project including the formation of a team of outside reviewers, but no formal cost/benefit evaluation of TIGER was ever conducted. 


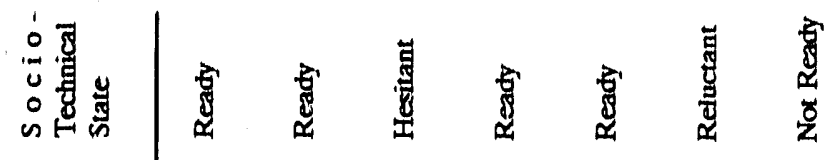

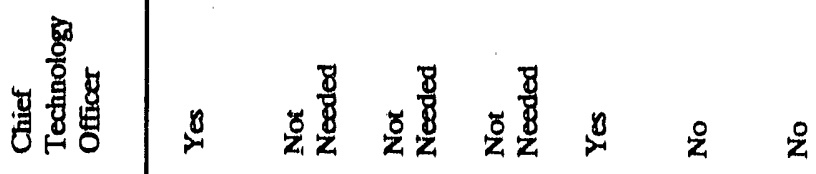
เป

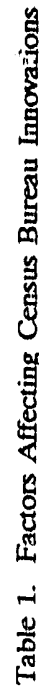

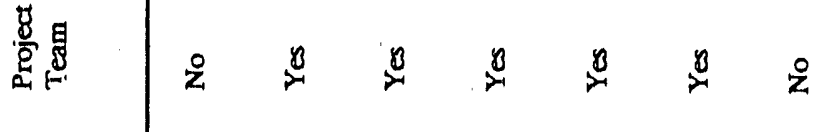

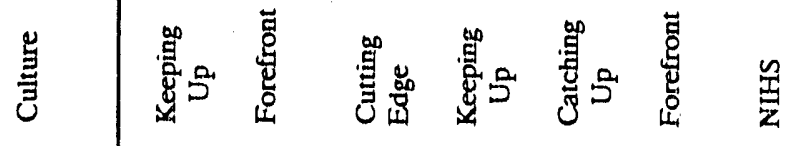

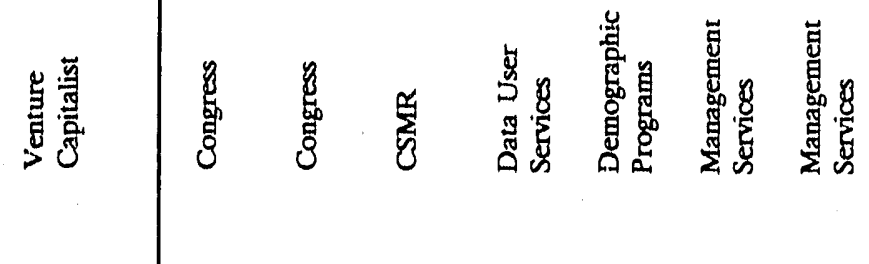

告

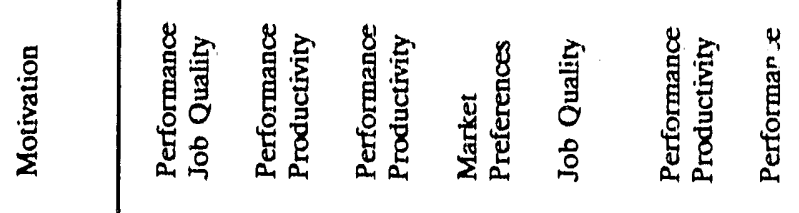

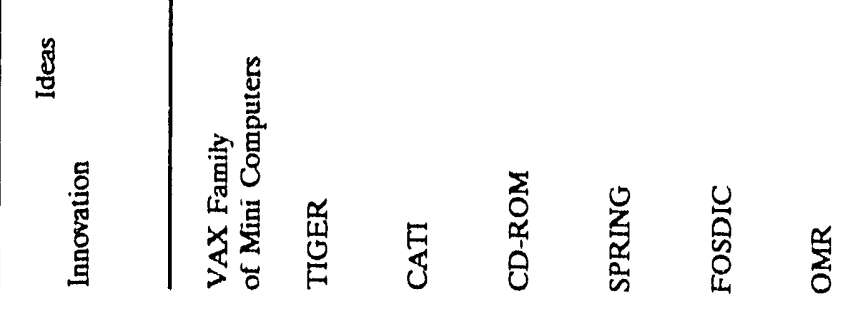




\subsubsection{Computer Assisted Telephone Interviewing}

CATI was first developed in the Statistical Standards and Methodology Directorate before its responsibility was transferred to the Field Division. Its goal is to improve the productivity of the telephone interviewing process. Several Bureau staff support CATI and jointly can be said to be its champion. The Statistical Standards and Methodology Directorate provided initial funding, assembled the initial project team, and set the tone for the project, to be at the cutting edge of field technology. CATI has been developed, implemented, and evaluated in stages. The Ficld Division was reluctant at first to pursue CATI, but has since come to appreciate its value. As with the rest of the innovations to be reviewed, a chief technology officer-type was not involved with CATI.

\subsubsection{CD-ROM}

The CD-ROM technology being developed by the Data User Services Division (DUSD) is motivated by the preferences of data users external to the Bureau. This is the only case of innovation motivated directly by factors outside the Bureau. The technology has a champion, was funded by DUSD, and benefitted from a good project team. Given that the market for Census data products motivated work on this technology, it can be viewed that DUSD is trying to keep up with technology. Much to its credit, DUSD seems more than willing to change to meet its market's needs. Again, no formal cost/benefit evaluation of the project was performed before the project was implemented. Instead, a carefully staged implementation plan was followed and an evaluation was conducted of the Technology's first field testing. 


\subsubsection{SPRING}

SPRING is in its initial prototype phase at the time of this writing. The Vision is that SPRING will improve the lives of the hundreds of analysts in the Demographic Programs area. There is very much the feeling that some catching up needs to be done and this part of the Burcau is more than ready to do so. In a rare example, SPRING's champion is also the venture capitalist and is performing some of the roles of the chief technology officer. The project team consists of experienced innovators. Like the other projects, no formal evaluation of the project has been conducted but Bureau staff have engaged in rigorous discussions about the project.

\subsubsection{FOSDIC and Optical Mark Recognition}

The term FOSDIC is being used here to refer to the entire data capture process being used in the 1990 Census. We consider FOSDIC an innovation because the technology has changed markedly this decade and because the Bureau is the sole developer of the technology. FOSDIC is motivated by performance and productivity goals. This technology has a long-time champion and is funded by the Management Services area. It is at the forefront of optical mark recognition and benefitted from a veteran project team. The Bureau was reluctant to use the technology for the 1990 Census for two reasons. One, the success of the entire 1990 Census depended on the champion, the major source of the FOSDIC knowledge. Two, some Bureau staff believed that competing technologies, even just key-entering all data, seemed to hold more potential.

One of the competing technologies was an Optical Mark Recognition (OMR) system developed in the private sector. This system was attractive because the private sector could always maintain the technology. The Bureau could buy it off the shelf. The OMR technology was tested during the 1985 Tampa Dress Rehearsal and was judged a failure. Technically, the equipment was 
judged unreliable and not developed enough to meet the specilicaitons of Census survey forms for size and paper quality, which some in the Bureau believe were too strict. The evaluation was done primarily by Management Services, which is the home of FOSDIC's champion. The National Institute for Standards and Technology confirmed the findings of the evaluation. The Bureau as a whole was not ready to fight for the OMR technology and this technology had no champion. After awhile, a consensus was formed that FOSDIC was the technology of choice for the 1990) Decennial Census.

\subsubsection{General Observations}

What general conclusions can be drawn from observations made about the seven technologies? First, the Bureau is sufficiently motivated by non-competitive forces to innovate. Second, it is not absolutely necessary for the technology to have a champion if a Burcau consensus can be reached. However, a crisis needs to be looming or to have just occurred for a innovation to succeed without a champion.

Venture capital is necessary, especially for projects that need a proof-of-concept phase. Those funds seem to be available. Congress is an option that the Bureau has successfully chosen two times for big projects. The Bureau has a mixed culture. Basically, the Bureau is motivated to keep up, and will be in the forefront if absolutely necessary to achieve immediate program objectives. There is not much evidence of risk taking or an entrepenurial spirit on technologies some might consider blue-sky.

Forming project teams was not a problem and the new venture unit approach was not really used. The organization itself did not appear to hinder these innovations, although comments from interviews reported in the next section provide a much different perspective. A chicf technology 
officer-type is not absolutely necessary for innovation on a small-scale, but is necessary on a large scale. In no case were formal cost/henefit evaluations conducted, although in all instances Bureau staff engaged in rigorous discussions about the projects and in several instances the technology was tested in stages. It is unclear whether the lack of formal evaluations hindered or maybe freed up the decision making process on innovations.

\subsection{SUMMARY OF INTERVIEW COMMENTS}

This subsection cummaries comments gathered during the interviews with Burcau staff about Census Bureau technology innovation and management. The comments represent opinions about the Bureau made by Bureau staff. The largely negative comments may be due to the interview process which was geared to identily what problems need attention. The generally positive review of Bureau innovations in the previous section and this section combine to provide a balanced picture of Census Bureau technology innovation and management.

To help organize the comments, they are categorized by their relationship to the nine idests introduced in Sect. 2.1. Figure 2 shows this categorization. The numbers in the boxes indicate the importance ORNL places on the idea given the set of comments, where \#1-Sociotechnical State is the most important and \#9-Champions is the least important. In other words, the Bureau needs to address issues associated with its Sociotechnical State more than it necds to address Champions. The recommendations in Sect. 4.0 are designed to help the Bureau overeome the many concerns documented below.

The central concern of Bureau staff has to do with the Bureau's sociotechnical state. People are too busy. The procurement process is an albatross. Communications do not flow smoothly within the Bureau. The consensus style of management slows decision making. The 
organization is slow to learn new technologies. There is too much outside oversight and the Bureau has too many planners. There are lead time problems, which are compounded by high Bureau personnel turnover and legislative constraints (e.g., on data confidentiality). With respect to technology, many computer software systems designed to store, retrieve, and manipulate data are virtually impossible to change. There is a feeling that in many cases, computer programmers have just run amuck, parlly because they are hard to manage, partly because programmers are given poor specifications. These comments exhibit a high level of frustration. Clear motivations and a determined culture could overcome these frustrations, but the comments in these two areas are mostly critical. With respect to motivations, comments indicated that motivations differ between demographic and economic programs and even between divisions within major programs. Dilfering motivations often lead to conflicts about technology decisions, with FOSDIC being the prime example. Interestingly enough, the interviews did not elicit clear statements of motivations for any program or division. It must be pointed out that the interviews didn't concentrate too much on this topic.

With respect to culture, everybody interviewed believed that his or her area contains people with good, new ideas. However, it is generally believed that the Bureau does not have an R\&D culture, or even subculture. Several people were critical of the "not invented here syndrome," but none seemed to suffer from it themselves. There were comments that the federal government does not promote a culture for long-term planning, which would be amenable to innovation. Lastly, there was no agreement whether technology should help dictate the form of the Decennial Census or whether the Decennial's requirements should drive the development of new technology.

These divergent viewpoints cannot help but clash in technology innovation discussions. A chief technology officer could help provide the leadership to sharpen motivations and resolve 
cultural differences. No such position exists in the Bureau and the comments indicate that this kind of leadership is not being provided. The Executive Staff, it was reported, ends up making technological decisions its members may not be qualifled to make. Leadership could have reduced some of the controversy surrounding the FOSDIC decision. The Bureau could improve its interactions with the Department of Commerce on technology issues and its ability to ask for enough money to get the job done right. In the past, ADP services has taken the lead in many technical areas. However, comments indicated that ADP services could be doing more in setting ADP standards, understanding the Bureau's technical needs, and working with the entire Burcau to better design, test, and implement new technologies.

Along this line, ADP services once played the role of the new venture unit, helping to pioneer the use of mainframes and the development of data capture equipment. Today, comments from outside ADP services indicate that this is no longer the case. Those within ADP services would argue and point to the family of ninicomputers, improvements in Bureau-wide file transfer, the Information Engineering Staff (sec: Appendix A for a description), and the microcomputer information center. Never-the-less, raany divisions feel they are going it alone.

In contrast to the discussion of isect. 3.2, many comments related to the difficulty of putting together project teams. It is hard to hire highly qualified technical people. It is hard to get outside help in time because of the procurement process. Even then it is hard to work with industry on new technologies because there is no guarantee to a company that the Burcau can acquire their technology. This is due to the competitive procurement process. There is a deep suspicion of contractors, and universities have not been responsive to Bureau requirements. These comments, as well as those made above, seem to indicate that the Bureau has been unable to capitalize on some additional innovation opportunities. 

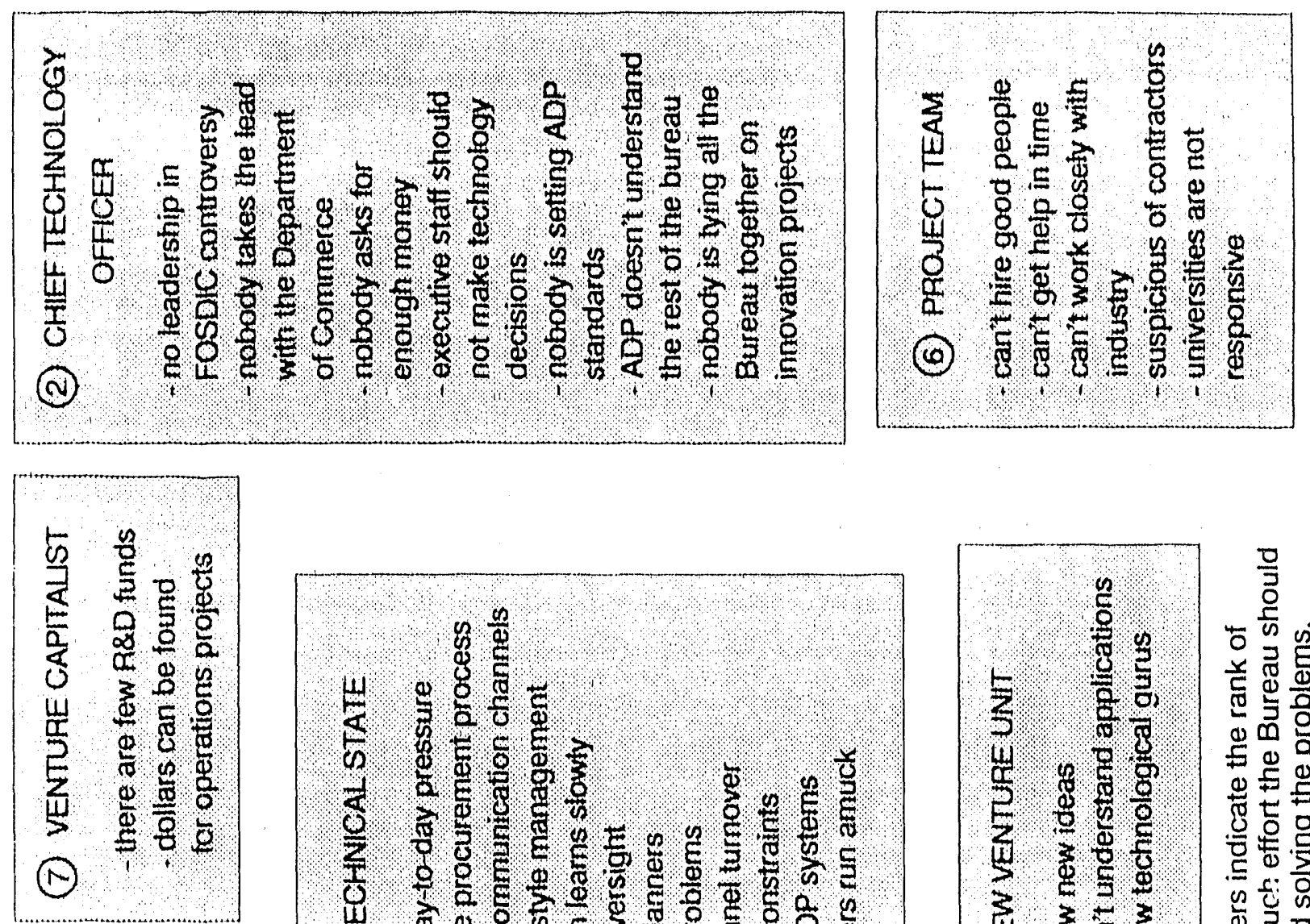
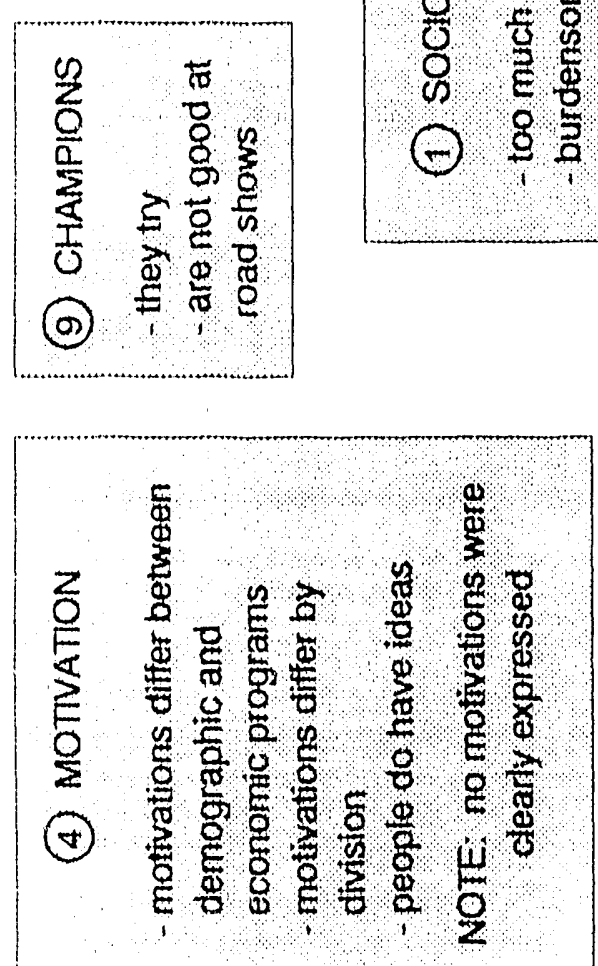
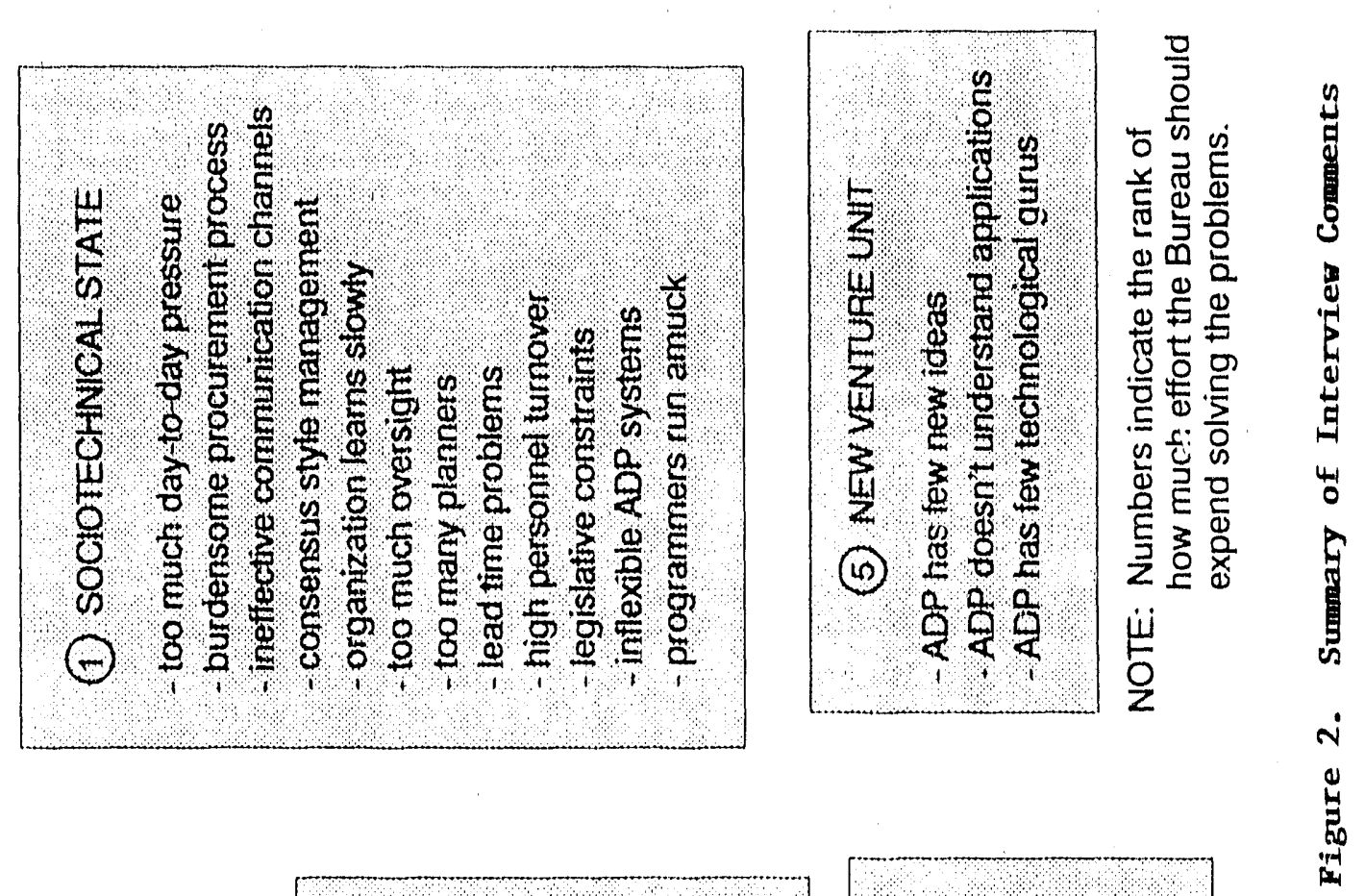

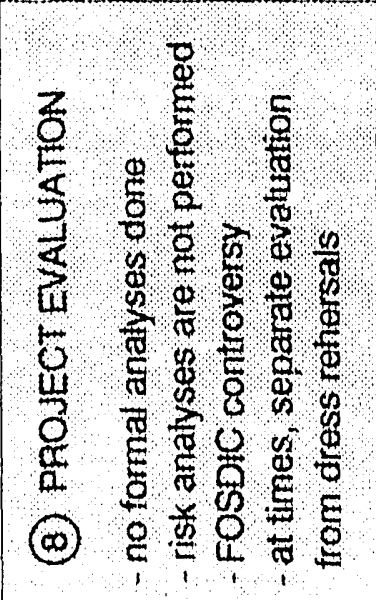


The only problem with venture capital is that it is difficult to obtain for a real research-oriented innovation. There are no daring projects similar to those funded by the Defense Department's venture capital outfit, the Defense Advanced Research Projects Agency (DARPA). Money seems to be available for more down to earth projects.

The only comments on champions are that they try but are not good at giving road shows. This is because technology champions often are unable to communicate in non-jargony terms with manager-type individuals.

The last area is project evaluation. Formal cost/benefit evaluations are rarely done. Risk analyses are not performed. Talking through problems seems to be the preferred mode of evaluation. A lengthy discussion was prepared justifying the FOSDIC decision, but this seems to be the exception rather than the rule. Many indicated that it is imperative to conduct evaluations of new technologies separate from the Decennial Census tests and dress rehearsals.

Overall, ORNL was not surprised at the comments. The frustrations of working in large organizations and working with the federal procurement process are legendary. Turf battles and differences of opinion cannot be avoided. The feeling that the Bureau lacks a technology leader is shared by many other public organizations (Mechling 1989). In many ways, large organizations are undergoing a learning process with the new, decentralized information technologies. It is hard to lead an organization if the path is unclear.

The only unexpected comments related to the Bureau's lack of $R \& D$ activities. One major use of Census data is for research. Researchers sit on every Bureau committee of outside advisors. In fact, the Bureau has led the way in data capture and mainframe tecinologies. Given the research environment that surrounds the Bureau and its past history in innovation, its current lack of R\&D work is surprising. The flame still burns but the lack of R\&D is a fact. 


\subsection{SUMMARY}

This section indicates that the Census Bureau has a very strong and diverse technological base. A lot of hard work has gone into designing, developing, procuring the components of, and managing the technological base. We have also seen that the Bureau has made progress with innovation. Six major innovations were identified. Many things are working well in the Bureau, providing motivation. At times, it is the desire to catch up with the rest of the world. At other times, innovation is borne of crisis. In any case, innovations can survive without all the ingredients mentioned in Sect. 2.0 .

On the other hand, comments from Bureau staff seem to indicate that much more could have been accomplished. Serious problems work against innovation and good technology management. The numbers in the boxes of Fig. 2 rank our opinions of the seriousness of the problems. Number 1 is the sociotechnical state of the Bureau. It sounds like a typical federal organization, which is very difficult to mold towards perfection. The second most serious problem is leadership, figuratively represented by the image of a chief technology officer. It is not a requirement for the Bureau to have a chief technology officer, but someovie or some organization(s) needs to fill the leadership role. Leadership could help overcome problems 3, 4, and 5, dealing with culture, motivation, and new venture units, respectively. Progress can be made on the other problems, but they are not seen as serious as the first five.

A final comment pertains to the nature of the innovations themselves. In every case, they represent an automation or an attempt to automate existing Bureau processes. For example, the goal of CATI is to assist telephone interviewers with their current jobs, not to facilitate a wholly innovative interviewing process. The microVaxes in the District Offices are designed, for example, 
to help keep payroll and track survey returns, not to facilitate a major reconceptualization of how to take the 1990 Decennial Census. The TIGER System is designed to assist development of the address list similar to the way it was done for the 1980 Decennial Census, not to initiate a major change in that process. In no case can the new technology be said to represent a strategic change in how the Bureau accomplishes its job or in how the Bureau conceptualizes its job. We hope that in the future consideration will be given to how the Bureau and its tasks can be reinvented to take advantage of new technologies. 


\subsection{RECOMMENDATIONS}

This section presents five major recommendations designed to promote technology innovation and facilitate technology management in the Census Bureau. The recommendations encompass most of the standard ideas presented in the technology management literature (e.g., Wolcoff et al. 1983). As a set, they focus on continuing the process of technology decentralization in the Bureau and, therefore, concentrate on involving the entire Bureau' in major technology decisions. The first pertains to how responsibilities for technology should be allocated among the Bureau's divisions and proposes the formation of a Technology Forum. The second advises the formation of a Technology Review Committee to gain more outside perspective and expertise. Third, innovations can be spurred on by the identification of Technology Gurus. The fourth pertains to advertizing an informal Bureau technology innovation process. The fifth set of recommendations involves the establishment of an Advanced Technology Studies Staff. These recommendations are designed to be independent of one another, so that the implementation of one need not depend on the implementation of another. However, we believe that the value of the recommendations is greater as a set. 


\subsection{THE TECHNOLOGY FORUM}

It was found that numerous Bureau staff thought that the Bureau's sociotechnical state and leadership regarding technology could be improved. This subsection contains recommendations pertaining to the Bureau's organization which could lead to improved technology management. Figure 3 provides an organizational schematic that provides a point of reference for the recommendations. 


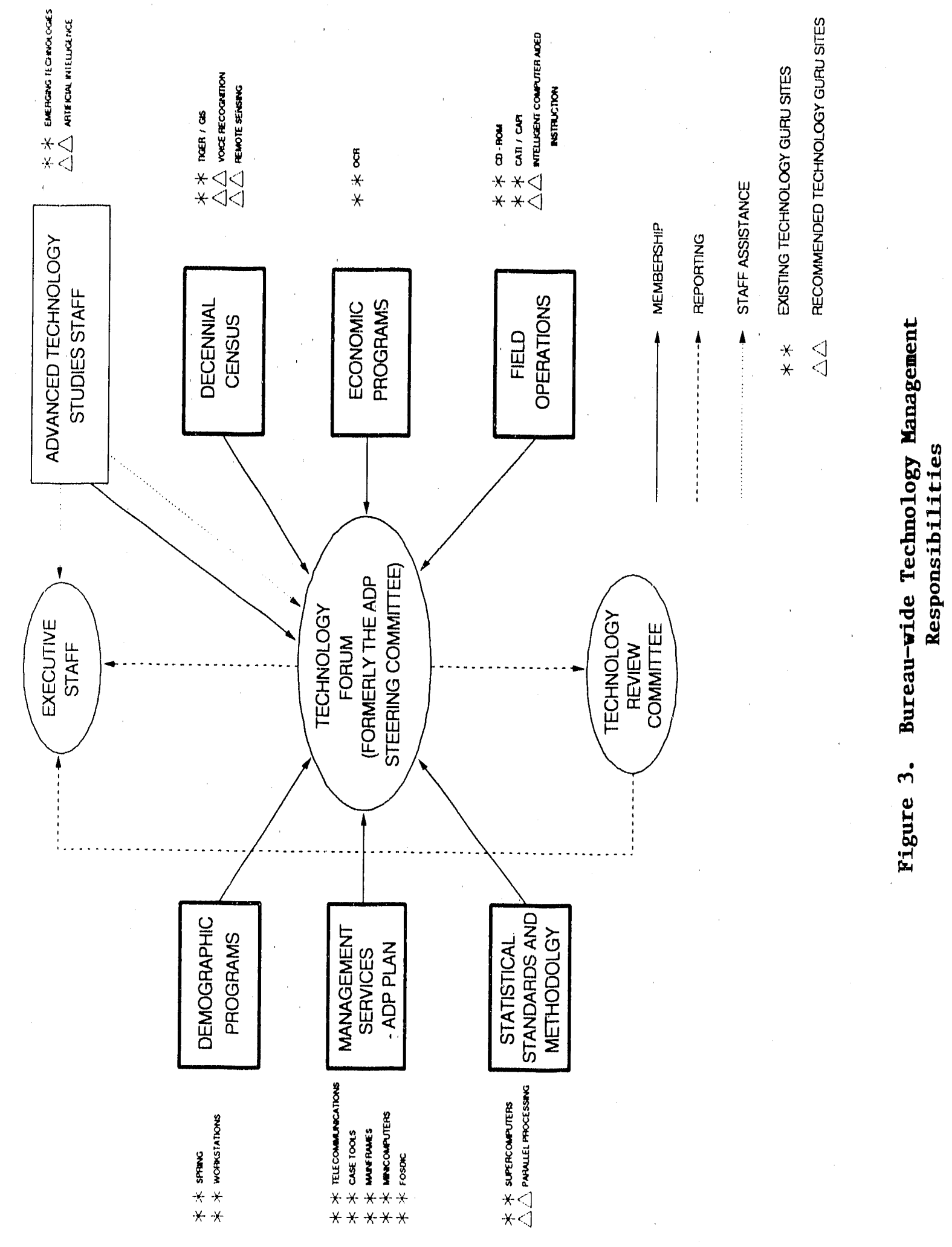


The most prominent recommendation regards the establishment of the Technology Forum, to take the place of the ADP Steering Committee. Currently, the Committee consists of 12 stalf members from across the Bureau who are interested in discussing computing issues. It is headed by ADP Services, which has a total of two members on the Committee. The Committee meets periodically to discuss technology issues. Its major function is to act as a sounding board for ADP Services' ideas and for ADP Services to collect ideas from the rest of the Bureaiu. The ADP Steering Committee has no formal authority. As such, it is difficult for the ADP Steering Committee to offer strong technical leadership to tackle sociotechnical problems.

The Technology Forum would consist of representatives from Divisions considered major technology users, and would act as a Board of Directors for technology (Umbaugh 1987). The representatives need to have technical backgrounds and must also have some authority to make decisions for his or her Division. We recommend that the head of the Forum represent an operations division within the Bureau, so that operations concerns are foremost in the discussions. The Decennial Operations Division would be a good candidate because it is the focus of major Decennial discussions and would be the natural link from Decennial operations to other areas of the Bureau.

The members of the Forum will openly discuss technology issues of importance to the Bureau and provide Bureau-wide "guiding light" leadership required to manage decentralized technology. One role of the Forum will be to present to the Executive Stalf recommendations for major new technological policies. For example, the Forum would recommend to the Executive Staff the approval of a policy to move to interactive computer systems for data analysis. The Forum could also ask the Executive Staff for approval of a general method to pay for inter-directorate computer systems and an allocation of computer resources that need to be shared across the 
Bureau. The Forum would decide on specific approaches to sharing the funding and resources. In this way, the Executive Staff will need only to set policy, not render detailed technological decisions. Specific computer system issues confined within specific directorates may not be appropriate for the Technology Forum.

The Forum should also act as an advocate of innovation. The Bureau should consider allocating to the Forum funds to support innovation, although the Forum should not be considered the only source of innovation funds. In return, the members of the Forum should be willing to help innovations overcome sociotechnical barriers. The Forum will also manage the evaluation of innovations it funds, although the evaluations themselves should be done by stafl that are designated by the Bureau to assist the Forum.

The Forum will meet on a regular basis, possibly once or twice a month. It is recommended that the Forum have a special room, equipped with the latest in decision support technology (c.g., computerized note-taking and voting system, video-conferencing). The Department of Commerce has such a room, so this idea has strong precedent. If possible, the room should be large enough and/or the technology flexible enough to allow other interested Bureau staff to listen to and possibly take part in technology discussions. If this could be done, then it would be a true Forum, where ideas and concerns could be widely exchanged. Bureau communications could improve dramatically and Bureau-wide problems could be comprehensively addressed.

It is not the intention that Forum members spend all their time meeting in the Forum. Given the complexity of the issues, the Bureau needs to assign responsibility for providing staff support to the Forum. For example, the Forum could request cost estimates for new proiects and require unbiased pre-project and post-project evaluations. ADP Services could have this 
responsibility, or as recommended in Sect. 4.5, the ATSS could fill this role. Of course, each Forum member could also rely on the resources of his or her Division.

Management Services will continue to be the keeper of the ADP Plan. It is important for this responsibility to remain where it is because the ADP Plan is inextricably tied to procurement issues, and Management Services needs to continue to provide centralized, technology-based services. The Forum will provide input into the plan regarding funds for technology R\&D and long-range technological trends.

Management services will also retain responsibility for setting technology standards, as advised by the Forum. Standards are useful for various reasons. First, standards could speed up the procurement process. For example, if every division in the Bureau used personal computers with the same operating systems, then fewer and larger orders could be placed and sole source purchases could be more easily defended. Second, standards are important for connectivity. One way to improve communication Bureau-wide is through electronic mail but this will not be feasible if standards for electronic mail are not utilized. The National Institute for Standards and Technology could provide input into standards setting.

Management Services will also be responsible for the overall planning of information networks in the Bureau. Thus, instead of having as a major goal the fostering of specific technologies, its major goal would be to make sure that information can move efficiently anywhere in the Bureau. Sullivan and Smart (1987) state that more central ADP organizations are adopting this responsibility.

It is not recommended that the Bureau establish any other new committees to undertake technology issues. The keys to improving technology innovation and management in the Bureau are communication and a willingness of people to work toward the organization's goals and not the 
goals of suborganizations. If the Forum opens up communications and promotes Burcau-wide cooperation, then the Bureau can move forward without additional formal committecs.

Tuble 2, first row, summarizes how the Forum will help improve Bureau technology innovation and management. Its chief roles will be to provide leadership and help overcome sociotechnical state problems. In essence, the Forum will be the Bureau's Chief Technology Officer. To a much lesser degree, the Forum will act as a venture capitalist, and help improve the Bureau's culture for innovation. The Forum will also be involved in managing project evaluations.

\subsection{TECHNOLOGY REVIEW COMMITTEE}

It is recommended that the Bureau assemble a Technology Review Committee (TRC) consisting of experts from outside the Bureau. The TRC would periodically review the Bureau's technology base and plans for new technology. If a Technology Forum were in existence, it would be especially convenient for the TRC to meet with the members of the Forum, maybe even in a forum atmosphere. The TRC will formally report its findings and observations to the Executive Staff, although it should be understood that the report will influence technology innovation and management Bureau-wide. 


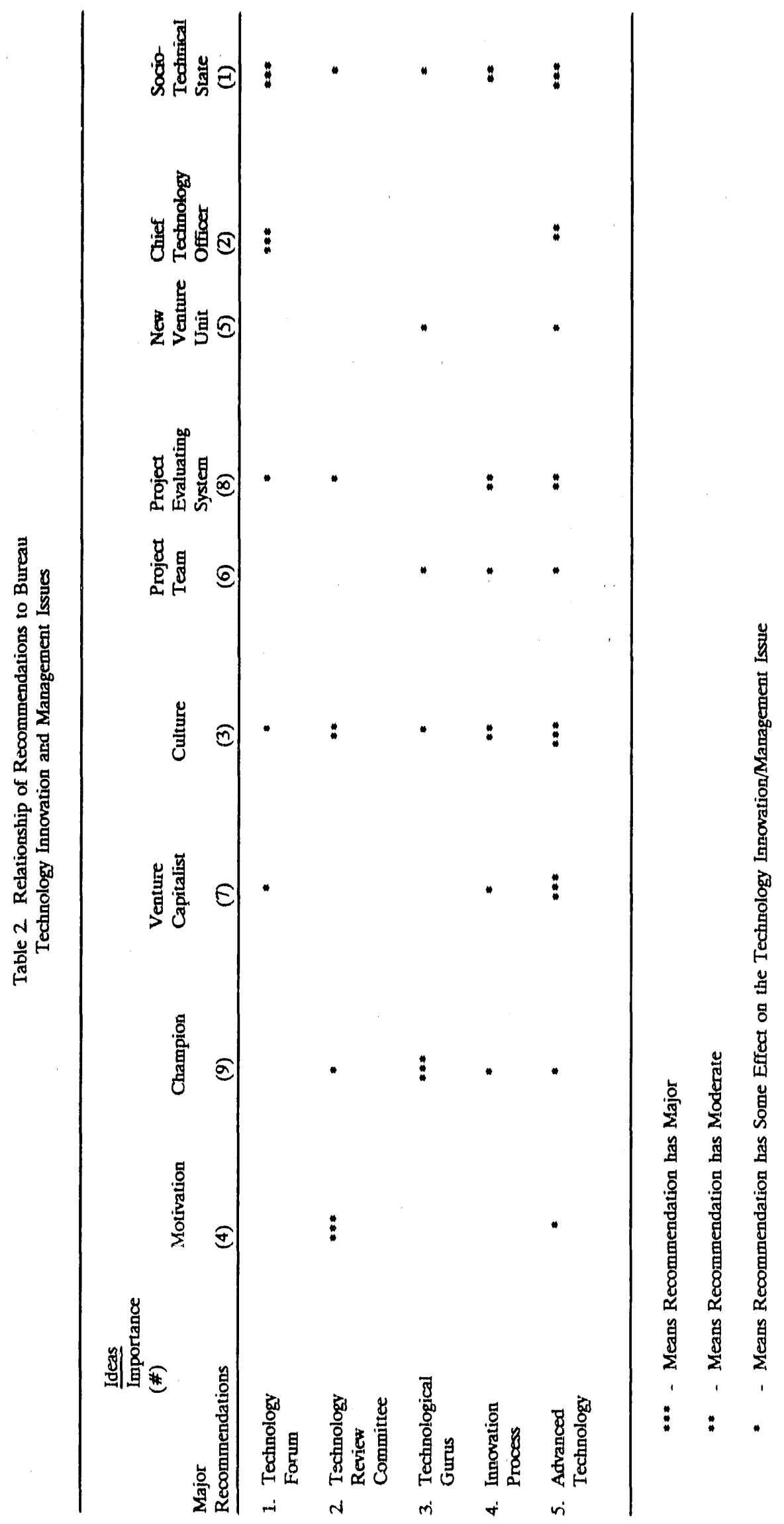


The Bureau has other advisory committees, such as in the areas of economics and statistics, which perform analogous functions to the proposed TRC but are too formal for tochnology issucs. That is, the TRC should not have any authority to impose technology decisions upon the Bureau nor should its constitution become a political issue. Instead, the TRC will be most valuable if it is nonpolitical and focused on helping the Bureau solve technical questions. The Burcau needs to find committee members it feels comfortable working with and who can contributemost to technical discussions. Thus, the TRC members should be appointed by the Bureau itself,by the Executive Staff for example, with recommendations from the Forum, and/or ADP Services and other Divisions.

The value of the Technology Review Committee will outweigh the negatives associated with preparing presentations and submitting the Bureau to one more outside review process. As indicated in Table 2, the TRC will help overcome at least five specific problems. Most importantly, the TRC will provide motivation for the Bureau to do more than just keep up with technology. This motivation will also affect the Bureau's culture. It is possible that TRC recommendations will address R\&D projects, just as the recommendations in this report. TRC presentations will help champions emerge and/or assert themselves. The review process will provide another way to improve the project evaluation process. Finally, the TRC should be directed to field comments and complaints from Bureau staff about sociotechnical problems with technology innovation and management in the Bureau. In turn, this information should find its way into TRC reports and given to the Executive Staff. 


\subsection{TECHNOLOGY GURUS}

The third major recommendation is to have the Bureau designate technology gurus. Gurus will be responsible for being Bureau experts in a innovative technology of interest to the Burcau. For example, gurus could be designated in the areas of CASE tools, telecommunications, and supercomputing (see Fig. 3 for additional suggestions), Gurus could reside anywhere in the Bureau. Designations can be made by the Executive Staff, the Forum, if there is one, or by the ATSS, if there is one.

Gurus are not necessarily technology champions, as the latter are delined in Sect. 2.1. The champion is the person who pushes an innovation from beginning to end. The champion makes the presentations and engages in the arguments. The responsil ility of the guru is to know the technology inside and out. What can it do? How reliable is it? What does it cost? A champion will need a technology guru to help answer technology questions and to participate in prototyping projects. In some cases, and maybe even in a majority of cases in the Bureau, the champion and guru will be the same person. Gurus instead of champions should be anointed because the Bureau should have on-hand ready access to technological expertise if and when a champion or the Bureau decides to establish a project in the area.

Gurus would be given some additional resources and/or some release time to enable them to become truly proficient with a technology vital to the Bureau. In return, the gurus will be expected to be available to anyone in the Bureau to answer questions about the technology. In particular, the Gurus would be responsible for providing information to the Forum and the Exccutive Staff. As indicated on Fig. 2, several de facto guru sites already exist in the Burcau. For example, the TIGER guru resides in the Decennial Census Directorate and the CATI guru resides in the Field Division. New gurus could be anointed in the areas of parallel processing and 
intelligent computer aided instruction and reside in the Statistic Standards and Methodology Directorate and the Field Division, respectively.

Gurus help solve many problems associated with finding and supporting new technologies. In-so-far as gurus are themselves champions, the process clearly identifies champions, and if handled properly, provides job rewards for being a champion. Designating gurus helps improve the Burcau's technological culture by regularly focusing discussions on new technologies and by ensuring that technological expertise is readily available. Resources available to a guru will help initiate new projects and a champion/guru would be the logical focus for a new venture unit. Lastly, a guru, by virtue of the title may be better able to deal with organizational barriers to transferring new technology into the Bureau.

\subsection{PROCESS FOR TECHNOLOGICAL INNOVATION}

The Census Bureau has several innovative achievements to its credit in the 198()s. Strictly speaking, in no case did an innovation proceed along the path introduced in Sect. 2.1, where: an idea was generated, a champion accepted advocate responsibility, proposals were made to funding sources for prototype projects, a project team and possibly a new venture unit was established, a chief technology officer ushered the innovation through tough organizational barriers, and then funding and other resources were obtained to implement the innovation organization-wide. The different innovation paths followed by the Bureau may in fact obscure the development of a common understanding of how to achieve innovation. Understanding a basic but flexible innovation process will help demystify innovation, improve communication and actually promote innovation. This subsection presents a technological innovation process for the Census Bureau. 
As shown in Fig. 4, the process begins with an idea for a technological innovation. The idea then begins a tortuous progression. First, the idea must pass muster within its division. Is it of potential value to the division? If implemented, what would be its cost? Can Bureau staff be found to manage, operate, and maintain the technology? An idea generated by a staff organizati in would need to have affirmative answers to these questions, too, but on a Bureau-wide basis. Second, the idea needs funding. The division could allocate some of its resources for a small proof-of-concept project. The Forum and, as discussed in the next subsection, ATSS could also provide funding. If no funding is available, the idea will die.

Third, resources must be obtained with the funding. Resources include people and equipment. Resources can be found within the division, in other divisions, through direct contacts between the division and the outside, and indirectly through other division's outside contacts.

Fourth, the proof-of-concept technology undergoes an evaluation. If the division is the sole source of funding, resources and benefits of the technology, then the division could undertake its own evaluation. However, projects funded by the Forum or the ATSS or more than one division may require the appointment of an unbiased reviewer to conduct the evaluation. The technology should be evaluated over several criteria. Did it work as planned? If not, are the problems surmountable? Did the technology show potential? Was it difficult to use? Will it be difficult to procure? If most of the answers to these questions sound positive, then the idea shouldpass into the next phase. If the technology is new to the Bureau, at this point a technology guru may be appointed. 
WITHIN DIVISION

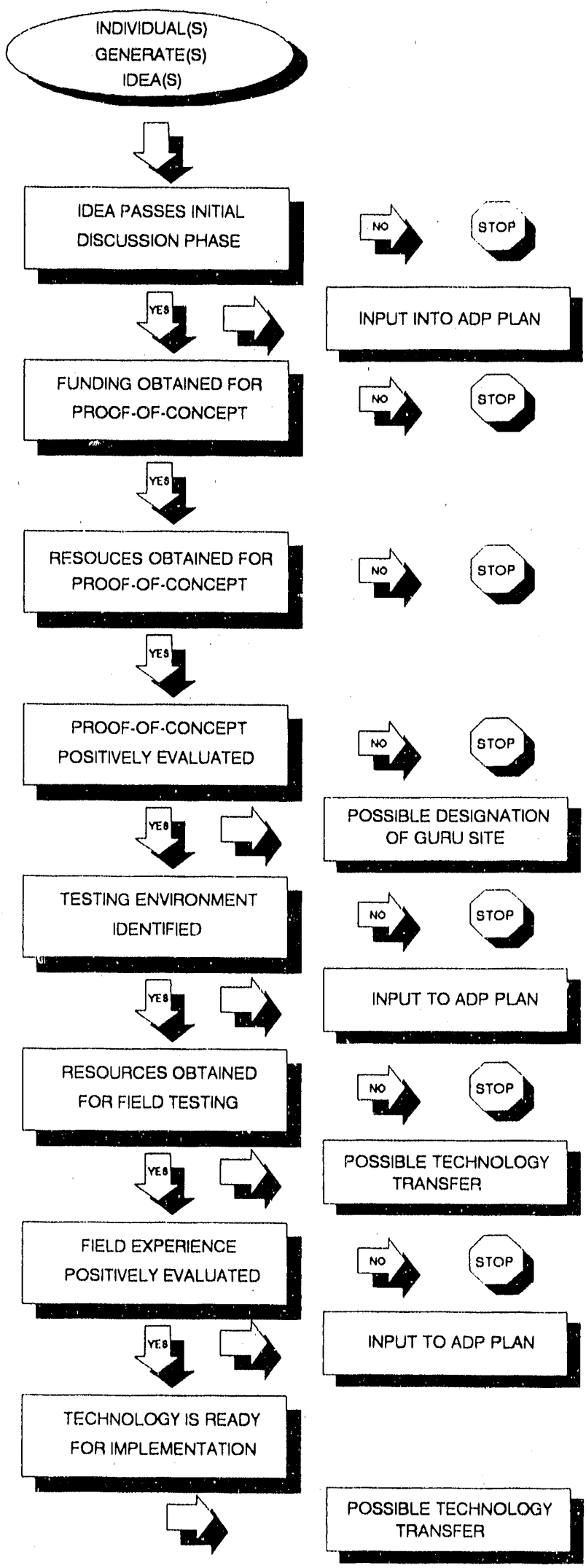

Figure 4. Technological Innovation in the Census Bureau 
Fifth, the technology must be tested in a field environment. Can one be found? Both Demographic Programs and Economic/Agricultural Programs expressed a willingness to provide testing environments for Decennial technologies. Other organizations in the government could provide testing environments and, as a last resort, elaborate simulated environments could be developed. This might be a good idea if the Bureau wants to experiment with a wholly automated District Office for the Year 2000 Census. Also at this point, since the Bureau is now serious about the technology, the idea should find its way into the ADP Plan.

Once a testing environment has been identified, the sixth step involves finding funding and resources. At this point, the project may be too large for internal funding. Congressional appropriations must be considered. On the other hand, for smaller projects, funding would most likely be obtained from the division or from a number of other divisions. As the project progresses, plans to transfer the technology to the operating divisions, if indeed that division(s) is not managing the project, must be made.

The seventh step involves an evaluation of the field experiment. In addition to the questions posed in the first formal evaluation, the technology should be reviewed with respect to its ability to scale-up, its reliability, its ability to merge into an operation, and its overall cost. If the idea passes this test, it is ready for implementation and should then become the sole responsibility of the relevant operations divisions.

It is recommended that the Bureau advertise this innovation process, not formalize it. The Bureau only needs to inform staff about the process to derive benefits from it. These benefits include the facilitation of sociotechnical processes and the strengthening of the Bureau's innovation culture. The process also has evaluation directly incorporated at logical points. The innovation process does not require formal evaluations, although ORNL strongly recommends that a few 
Bureau staff explore some of the evaluation ideas mentioned in Sect. 2.3. The innovation process will help would-be champions, would-be venture capitalists, and would-be project members understand the process consequences of their decisions.

\subsection{ADVANCED TECHNOLOGY STUDIES STAFF}

It is recommended that an Advanced Technology Studies Staff (ATSS) be established within the Census Bureau. Its basic responsibility will be to promote technological innovation in the Census Bureau. Ways to accomplish this task are described below. The staff should consist of a leader, permanent staff of three or four, and a temporary staff of three or four. The leader should possess a broad knowledge of all Bureau operations, be able to understand new technologies, and translate technological information into forms understandable by non-technologist Bureau managers. The permanent staff should possess a mix of technological, operational, and organizational skills so that they can help evaluatc the Bureau-wide potential of new technologies. The temporary staff can be drawn from other Bureau divisions, either by direct assignment or by a fellowship program. These people would use their time with the ATSS to learn about new technologies and then bring their experiences back to their divisions.

The ATSS should be a member of the Forum, where the ATSS would act as an advocate for new technologies and would be responsible for initiating and mediating arrangements between divisions with respect to technology. For instance, the Decennial Operations Division may wish to test a new technology, not in a formal dress rehearsal exercise, but in the field with a demographic, economic, or agricultural survey. The ATSS would help remove any roadblocks preventing such a beneficial joint project. 
Numerous strategies and tactics are available to the ATSS to advocate technological innovation in the Bureau. One of the most importint involves funding. The ATSS should assume the leadership role for obtaining funding for research and development for technological innovation in those instances when other divisions find it difficult to request R\&D funds. The ATSS can also request funds for ideas and projects to demonstrate proof-of-concept technologies not yet supported by other divisions. Lastly, the ATSS should attempt to obtain funds for disbursement, on an application basis, to other divisions for emerging technologies. The ATSS should be a focal point for the Bureau and for oversight organizations for funding discussions and requests. For example, the Technology Review Committee could meet with ATSS staff to discuss long-range technology issues, as opposed to issues of more immediate concern for the Technology Forum. Through good work over time the Staff can develop a sound reputation which could help ensure a stable level of funding.

Most R\&D funds will be disbursed to various Bureau divisions, either by prior agreement or through an application process. However, on occasion, the ATSS could decide to establish its own projects if no divisions were interested. Emphasis would be on prototyping, which Owen (1989) states is the essence of pragmatic technology development. In these cases, it is recommended that the work be done by outside contractors or R\&D institutions within the Federal Government. This policy will ensure that the ATSS staff will not grow in size nor compete with the Bureau's other divisions. Also, if the project is highly technical and involves state-of-the-art technology, it would probably be much more efficient to have $R \& D$ institutions conduct work on prototype systems.

The ATSS could leverage its funding by working with other federal agencies on similar technology. For example, several agencies could provide funds to study automatic handwriting recognition systems. In these cases, it would be preferable to have a research institution receive 
all the funding and distribute research results to all the participating organizations. This arrangement works well in the private sector as witnessed by organizations as diverse as the Electric Power Research Institute and the Textile/Clothing Technology Corp. The ATSS could evaluate using existing national laboratories or even cosponsoring a Federally Funded Research and Development Center (FFRDC).

Even if the ATSS does not fund much work outside of the Bureau, it should accept the responsibility of establishing and maintaining formal relationships with technological organizations. For example, the ATSS could periodically visit the National Aeronautics and Space Administration or the Defense Advanced Research Projects Agency to learn about new technologies. The Department of Energy's national laboratories actively seek to transfer technologies into the private sector and there is no reason why they shouldn't be interested in transferring tachnologies within the public sector. New ideas can be transferred into the Bureau in other ways, too. For example, the ATSS could schedule special training sessions, sponsor workshops and on-site seminars, and regularly schedule technology demonstrations in a special technology room. The ATSS could also establish a technology library and reading room and electronic bulletin boards.

Along with funding responsibility, the ATSS should be responsible for destroying roadblocks in the way of technology innovation. On the other hand, the ATSS could support the Technology Forum by providing unbiased evaluations of technologies that may cut across organizational boundaries. The Bureau could well benefit by establishing expertise in formal project evaluation within the ATSS. The ATSS can handle these contradictory responsibilities if the ATSS is well-placed within the Bureau.

And where should the ATSS be placed within the Bureau? Four alternatives were considered. First, it could report directly to ADP Services. Second, it could report directly to an 
operations division, such as the Decennial Operations Division. 'Third, it could be independent and report directly to the Director/Deputy Director. Fourth, it could be part of the 21st Century Staff. The ATSS could accomplish most of the tasks listed above related to technology transfer given any of the above alternatives. However, to enable it to share a leadership role with the Technology Forum and to accomplish all of its tasks, a modified version of the fourth alternative is suggested.

Several important considerations will help explain this viewpoint. First, the ATSS needs to have a holistic view of the entire Bureau because often times technology cuts across Bureau boundaries. To be successful, its work needs to be viewed as unbiased and its findings need access to Bureau decision makers. This argues for direct access to the Director/Deputy Director's Office. Second, the ATSS would not have the time to act as an advocate for new technology if its staff become involved in day-to-day Bureau operations. This argues against placement in an operations division. Third, the ATSS is intended to be a small unit, responsible for ideas and only occasionally for hands-on work on developing new technologies, as explained below. This argues against having the ATSS report to ADP Services, which is concerned with having its staff work on operations projects. Placing the ATSS in another division might eventually diminish the staff's ability to generate ideas.

The ATSS could independently report to the Director/Deputy Director or become part of the 21st Century Staff. The 21st Century Staff is responsible for advanced planning for the Year 2000 Census and its existence beyond the early 1990s should not be assumed. Its concerns are also focused on the Decennial. The ATSS could report directly to the Director/Deputy Director but it may be too small to generate the critical mass necessary to make it a major player and it could benefit from the forward-thinking activities of the 21 st Century Staff. The recommendation is to include the ATSS in the 21st Century staff and to broaden the responsibilities of the 21st Century 
Staff to encompass advanced studies about all the Bureau's activities. The 21st Century Staff could be renamed to reflect its new role. This new organization could provide fellowships to individuals throughout the Bureau to work on long-term issues. Symbiosis with those concerned about technology will serve to enhance the value of the Staff's work.

It should be noted that the basic idea of the ATSS is contained in a 21st Century Planning Initiatives Issue Paper (U.S. Census Bureau, 1989). This document proposes the establishment of a small group of people to promote technology transfer in the Bureau. Its responsibilities were to include technology identification, information dissemination, and some prototype development work. Its placement in the Bureau was not discussed nor were its responsibilities as diverse as those envisioned for the ATSS.

In summary, if the ATSS recommendation is implemented, along with the above mentioned organizational change, the ATSS will help solve many of the Bureau's technology innovation and management problems, as indicated in the last row of Table 2. Most importantly, the ATSS will drive the Bureau's culture by being a technology advocate. It will be there to help solve sociotechnical problems, and will share with the Forum the Chief Technology Officer role. Given funds, it could become the Bureau's venture capitalist and conduct formal project evaluations, upon request. At times, the ATSS may serve as a new venture unit and help create project teams. Its existence will help motivate the Bureau and would-be champions. 


\subsection{SUMMARY AND DISCUSSION}

The recommendations presented in Sect. 4.0 will help the Census Bureau manage innovation and technological change. The Advanced Technology Studies Staff will provide a focus for innovation. It will help overcome numerous problems that stifle innovation. For example, it could manage $R \& D$ projects when other divisions do not have the time because of pressing day-to-day responsibilities. The ATSS could manage projects of value to the Decennial Census separate from formal dress rehearsals and in off-years to help reduce the lead time problem of deciding on new Decennial technologies. By providing evaluation services, the ATSS can offer unbiased, holistic judgments about the benefits of new technologies. Its advocating of innovation will ensure that the Bureau does not miss valuable opportunities to adopt new technologies.

The recommendations concerning the Bureau's organizational design are in no sense radical. Instead, they represent refinements to an existing, recently successful process. The Technology Forum is needed as a place for day-to-day managers from around the Bureau to discuss technology. The communication value represented by the Forum cannot be overestimated. The Technology Review Committee also underscores the Bureau's intent on making technology an important factor in Bureau operations. The guru sites formally recognize the current state of technological innovation in the Bureau.

The innovation process is not magical or novel. However, having it on paper and having key Bureau personnel share its meaning will help promote innovation in the Bureau. Everyone will know what the barriers are and where help can be obtained. With a clear plan, innovation can routinely be initiated and tracked, thereby pointing out areas for further improvement. 
No one knows what kind of technology the future will bring. The microcomputer revolution has changed the U.S. organizational landscape in less than a decade. The Defense Advanced Research Projects Agency predicts that the power of desktop computers of the next century will! be hundreds of times that of today's supercomputers. Advances in voice recognition and natural language processing offer tantalizing opportunities. The technology will grow and be available to those organizations prepared for technological change. It is hoped that the ideas presented in this report will help the Census Bureau be ready for the challenges and opportunities that lie ahead. 


\subsection{ACKNOWLEDGEMENTS}

The authors wish to thank Bob Hammond of the Bureau's 21st Century Staff for his efforts in managing this project. Both he and Bruce Johnson, Chief of the 21st Century Staff, provided valuable comments on the early drafts of this report. We wish to thank the staff of the Census Bureau who allocated some of their valuable time to the interview and report review process. Those individuals include: John Adkins, Marie Argana, Bryant Benton, Jack Beresford, Alan Berlinger, Richard Bitzer, John Blum, David Browne, Howard Bryant, Roger Bugenhagen, William Butz, Hy Chansky, Larry Charbaugh, Barry Cohen, Gerald Cranford, Rob Creecy, Don Dalzell, Dave Diskin, Mike Fortier, Nevins Frankel, Linda Franz, Paul Friday, Doug Hillmor, Gerard Iarnelli, Arnold Jackson, Louis Kincannon, John Lance, Tony Lesko, Arnold Levin, Richard Maier, Bob Marx, Stan Matchett, Tom Mesenbourg, Susan Miskura, Quentin Newhouse, Bill Norfolk, Len Norry, Sandra Rowland, Paula Schneider, Ron Steinberg, John Thompson, Jay Waite, and Forrest Williams. We would also like to thank those Census Bureau staff who provided comments on the Draft Report. Dave Drake of Applied Management Sciences also provided valuable comments on the Draft Report.

$$
61 / 4
$$




\subsection{REFERENCES}

Bart, C. 1988. "New Venture Units: Use Them Wisely to Manage Innovation," Sloan Management Review, 29, 35.43. R

Butz, W. 1989. "SPRING: How to Get "There' from 'Here'", Internal Census Bureau Memorandum.

Chacko, G. 1988. Technology Management: Applications to Corporate Markets and Militury Missions. Praeger, New York, New York. D

Chisholm, R. 1988. "Introducing Advanced Technology into Public Organizations," Public Productivity Review, 11, 39-56. J

Crescenzi, A. 1988. "The Dark Side of Strategic IS Implementation," Information Strategy: The Executive's Journal, 5, 14-20, L

Donovan, J. 1988. "Beyond Chief Information Officer to Network Manager," Harvard Business Review, 88, 134-140. H

Gold, B. 1988. "Charting a Course to Superior Technology Evaluation," Sloan Management Review, 30, 19-28, Q

Lconard-Barton, D, 1987. "The Case for Integrative Innovation: An Expert System at Digital," Sloan Management Review, 29, 7-19. P

Marx, R. 1988. "The TIGER System: Six Years to Success" Developments in Land Information Management.

Mechling, J. 1989. "Putting the Pieces Together: Plenary Discussion on Technology and Organization in the Public Sector", Workshop V, Strategic Computing and Telecommunications in the Public Sector, John F. Kennedy School of Government, Harvard University, June 22-23.

Owen, D. 1989. "Prototyping: Essence of Pragmatic IS Development," Information Strategy: The Executive's Journal, 5, 21-25. M

Pearson, A. 1988. "Tough-Minded Ways to Get Innovative," Harvard Business Revicw, 88, 99-106. $\mathrm{G}$

Stecle, L. 1989. Managing Technology: The Strategic View. Mc-Graw-Hill, New York, New York. V

Sullivan, C. and Smart, J. 1987. "Planning for Information Networks," Sloan Management Review, $28,39-44$. N 
Umbaugh, R. 1987. "A Board of Directors for Information Services," Information Strategy: The Executive's Journal, 3, 25-31. U

U.S. Census Bureau 1989. "21st Century Planning Initiatives Issue Paper", prepared by the 21st Century Staff.

Wolcoff, C. et al. 1983. Techniques for Managing Technological Innovation. Butterworth Fublishers, Boston, MA. B 


\begin{abstract}
APPENDIX A
A draft report consisting of the four sections of this final report was circulated to every Census Bureau person interviewed for this project and to a small number of people outside of the Bureau, Sixteen people provided written comments on the draft report. Comments on minor inaccuracies in describing the Census Bureau and its technology have been addressed in the main body of the report. The major purpose of this appendix is to document reactions to the live recommendations presented in Sect. 4.0. This appendi. also provides an opportunity to address a few misconceptions about the recommendations and respond to some of the criticisms of the recommendations. This appendix concludes with a brief discussion addressing how the Bureau might implement the recommendations. It should be kept in mind that the Census Bureau, not ORNL, will have the last word on these recommendations.
\end{abstract}

\title{
A.1 COMMENTS ON REPORT AND RECOMMENDATIONS IN GENERAL
}

COMMENT: One reviewer commented that the report's definition of technology is too narrow. On page 2, technology is defined as "including any hardware, computer or otherwise, and advanced software which could be used by the Bureau in its daily operations." The concept of technology should have been defined to encompass "human processes and human factors aimed at improving the quality and productivity of our automated systems." This shortcoming resulted in ORNL overlooking the Bureau's Information Engineering Staff (IES) as a major Burcau innovation.

Briefly, the IES reports to the head of ADP Services and its mission is "to improve the quality and productivity of automated system development and maintenance by the introduction of improved/new methodologies (people related processes) and tools (software and hardware 
technology)." Establishment of the IES followed almost to a letter the innovation theory developed in Sect. 2. If the IES had been considered in the report as an innocation then its inclusion in Table 1, p. 28 would look like:

\begin{tabular}{|c|c|c|c|c|c|c|c|c|c|}
\hline Innovation & Motivation & Champion & $\begin{array}{l}\text { Venture } \\
\text { Capitalist }\end{array}$ & Culture & $\begin{array}{l}\text { Project } \\
\text { Team }\end{array}$ & $\begin{array}{l}\text { Project } \\
\text { Evaluating } \\
\text { System }\end{array}$ & $\begin{array}{l}\text { New } \\
\text { Venture } \\
\text { Unit }\end{array}$ & $\begin{array}{l}\text { Chief } \\
\text { Technology } \\
\text { Officer }\end{array}$ & $\begin{array}{l}\text { Socio- } \\
\text { Technical } \\
\text { State }\end{array}$ \\
\hline IES & $\begin{array}{l}\text { Productivity } \\
\text { Quality }\end{array}$ & Yes & $\begin{array}{l}\text { Mgt. } \\
\text { Services }\end{array}$ & Forefront & Yes & $\begin{array}{l}\text { Adhoc } \\
\text { Consensus; } \\
\text { Metrics }\end{array}$ & Yes & $\begin{array}{l}\text { Not in strict } \\
\text { sense }\end{array}$ & Reluctant \\
\hline
\end{tabular}

ORNL RESPONSE: Had ORNL been instructed to use a broader definition of technology that included organizational innovation, the IES would certainly have been included as an innovation. It is also good to illustrate that innovation is not restricted to technology but applies to any new idea that has potential impacts of any aspect of any organization.

COMMENT: The theoretical model of technology innovation and management presented in Sect. 2 was useful for many reviewers, although a few found it too abstract.

COMMENT: Sect. 3 did not mention communication problems among operating divisions with respect to technology innovation.

COMMENT: Sect. 3 does not do justice to how far the Bureau has progressed with technology during the last 3 to 5 years nor gives credit to the many people who have worked extremely hard over the years on technology projects and issues.

ORNL RESPONSE: These comments are well taken. Sect. 3.3 is largely negative because the interviews were designed to identify technology problems that need attention. The successful nature of six of the seven innovations discussed in Sect. 3.2 was designed to provide a positive balance to Sect. 3.3 . 


\section{A.2 COMMON MISCONCEPTIONS ABOUT THE RECOMMENDATIONS}

COMMENTS: Innovation cannot be mandated. A central area cannot handle innovation throughout the Bureau. ADP Services should not stand guard over technology advances. The ATSS should not do all the Bureau's innovation.

ORNL RESPONSE: We agree with all of these comments. Our view is that the Bureau will be best served by some central support of decentralized innovation. Every division should be able to pursue any innovation idea it so desires. However, not every division will have the resources or the technical expertise for pursuing each and every innovation idea. And there will be cases where an idea will effect more than one division and/or will need input and cooperation from other divisions. In these cases, divisions will benefit if the Bureau has some centralized function that can provide innovation resources. A centralized function would provide innovation services and promote and help coordinate interdivisional joint efforts, not be the innovation headquarters.

COMMENTS: The report does not draw upon Information Resource Management (IRM) ideas or regulations. The recommendations could be supplanted entirely with Dept. of Commerce IRM regulations. At the very least, the report's recommendations could pose some conflicts with IRM regulations.

ORNL RESPONSE: Although most of the Bureau's technology is designed to capture, store, and manipulate data, it must be made clear that technology is not the same as information and information is not technology. The recommendations in Sect 4.0 address issues of organizational design related to Bureau-wide technology management. IRM regulations and processes are designed only to facilitate management of information system projects. The Forum, for example, 
could ensure that IRM processes are followed for certain projects. However, such processes are in no way a substitute for the recommendations proposed herein.

\section{A.3 COMMENTS ON THE TECHNOLOGY FORUM RECOMMENDATION}

COMMENT: There is too much variation between the economic and demographic programs and between the censuses and sample surveys for the Technology Forum to work.

ORNL RESPONSE: Forums, like democracies, operate best in pluralistic settings. The fact that there are differences throughout the Bureau makes it even more imperative to devise ways for people to communicate with each other about any issue, not just technology.

COMMENT: Agree that the Technology Forum needs a more formal charter and more responsibilities than the ADP Steering Committee but the exact levels of the Forum's technical responsibility must be negotiated in such a way as to encourage a positive atmosphere between ADP Services and the Forum.

ORNL RESPONSE: We agree.

COMMENTS: Having someone from the Decennial Operations Division head the Forum would kill innovation and just wouldn't work. More consideration for the head of the Forum should be given to the person's skill and technical background than on what Division the person is from. Maybe the head of the Forum can be rotated on a yearly basis.

ORNL RESPONSE: The Technology Forum will help facilitate management of a decentralized technological base. The person or persons who will head the Forurn need to adopt this viewpoint. Exactly who is choosen to serve for what length of time is the Bureau's responsibility.

COMMENTS: Members of the Forum need to be tup-notch. Most of the really technically qualified people are in the ADP Services area. 
ORNL RESPONSE: We agree that the members of the Forum need to have technical backgrounds and be able to represent their Divisions in a suitable fashion. We do not think that most in the Bureau would agree that satisfactory candidates are not available throughout the Bureau. If this is the case, we strongly recommend that such people are to be hired by the Divisions. Decentralization of technology requires some decentralization of talent and resources.

COMMENT: Standards should be set at Division or Directorate levels but not Bureau-wide by ADP Services.

ORNL RESPONSE: Standard setting is a controversial subject. A key to addressing standards is identifying those technologies that should and should not be subjected to standard setting. Obviously, those technologies that constitute the Bureau's technological infrastructure need to be reviewed by ADP Services. The Forum would be an excellent place to discuss questions about standards.

COMMENT: Technology users should submit to the Forum new technology ideas. The Forum would then receive bids on providing the solutions and make sure that bureaucratic and procurement problems are kept to a minimum.

ORNL RESPONSE: This is a good idea about how the Forum would operate with respect to technological innovation. It captures the spririt of centrally assisted decentralized innovation.

\section{A.4 COMMENTS ON THE TECHNOLOGY REVIEW COMMITTEE RECOMMENDATION}

COMMENTS: This recommendation would avoid the in-breeding of ideas. It should be a benefit to the Bureau.

COMMENTS: Few people outside the Bureau understand the technical complexity of what the Bureau does. TRC members could never understand what the Bureau does. 
ORNL RESPONSE: Review committees can contribute valuable ideas to the Bureau without having to understand everybody's everyday jobs. We do appreciate that the Bureau has a difficult job. On the other hand, the review committee convened to assess the Challenger Space Shuttle accident did provide NASA with valuable insights.

COMMENT: Outsiders may not view Census Bureau technology as a priority. It may be better to work with one outside technical organization that can learn about the Bureau.

ORNL RESPONSE: These comments have value and should be kept in mind.

COMMENTS: A couple of reviewers stated that the Federal Advisory Committee Act regulations on outside review committees would prevent the establishment of an informal technology review committee.

ORNL RESPONSE: This would be a shame if true. If given the choice between having a formal, presidentially appointed review committee or no committee, we would recommend against having a committee. Technology should not be mixed with politics. However, we hope that there are other viable options.

COMMENT: Have the Technology Gurus sit on the review committee.

ORNL RESPONSE: Committee members may have to comment on management decisions and technology controversies. One reason to bring people in from the outside is to solicit comments that will not be colored by intraorganizational biases. The Gurus may indeed provide comments as sound or even better than outside people, but would they be taken seriously on such issues? It might be better for the Bureau to keep the Gurus as far away from these types of issues as possible. 


\section{A.5 COMMENTS ON THE TECHNOLOGY GURUS RECOMMENDATION}

COMMENTS: Designating gurus is a good idea, especially funding part of their jobs. This idea would make expertise more available throughout the Bureau.

COMMENTS: Good idea if coupled with a high-grade advanced technology position. Salary should be commensurate with expertise.

ORNL RESPONSE: We agree.

COMMENTS: Technology gurus already exist in the Demographic area. Gurus have existed in the Bureau for over a century; there is no management hole here. They already exist and there is no benefit in formalization.

ORNL RESPONSE: In some sense, these comments indicate that technology gurus represents only an incremental change from the present state of affairs. We would agree with this viewpoint. However, these comments do not persuade us that the incremental change is not worth exploring.

COMMENT: Gurus can't be designated, they just emerge.

ORNL RESPONSE: It is certainly reasonable not to designate a guru in some area until someone has emerged with at least an interest in the area. It is probably not wise to force an uninterested person to be a technology guru.

COMMENT: If a guru is supposed to uriderstand a technology inside and out and how it applies to the Census Bureau, the guru would be too busy to be a guru.

ORNL RESPONSE: We respectfully disagree with this comment.

COMMENTS: The term 'guru' is unprofessional; how about technical expert. How about the term 'internal expert.' 
ORNL RESPONSE: We purposely chose the term 'guru' because it has some life to it. Why keep everything so dry. On the other hand, we have no objections to these suggestions.

\section{A.6COMMENTS ON THE TECHNOLOGICAL INNOVATION PROCESS RECOMMENDATION}

COMMENTS: The process provides a sound framework for management control and decision making. It is a good idea. It is a good road map but needs to be accepted by key people in the Bureau.

COMMENT: The process has too many steps, it is too long for Census Bureau time schedules. ORNL RESPONSE: We hope that providing people with a road map will actually save time. COMMENT: The process is too simple for the Bureau. It is right out of Technology 101. ORNL RESPONSE: ORNL has proposed a core set of straightforward and doable recommendations tailored for the Census Bureau organization. The innovation process road map draws on our review of the leading business and management journals. Whether the process is viewed as simple or complex is not as important as whether it is viewed as having potential value for the Bureau.

\section{A.7COMMENTS ON THE ADVANCED TECHNOLOGY STUDIES STAFF RECOMMENDATION}

COMMENTS: Having the ATSS related in some way to the 21 st Century Staff (TCS) is self serving (because the TCS paid for the study). Keep the ATSS out of the TCS. This recommendation is obviously self-serving.

ORNL RESPONSE: We were prepared for this criticism. We are aware that many times ideas are not always judged soley on their potential benefits to the larger organization, in this case to 
the Census Bureau as a whole. Who presents ideas is sometimes more important than the value of the idea itself. However, we understand that the TCS may be moved in the organization to report to an Associate Director, not the Deputy Director. A different placement of the TCS in the organization may affect the placement of the ATSS. We stand by our recommendation, based on the organizational structure at that time, and the reasons supporting it, which are found in Sect. 4.5.

COMMENTS: The ATSS is a good idea but appears to overlap with the Information Engineering Staff (IES). Maybe the TCS, the IES and some components from the Demographic and Economic areas should be consolidated into the ATSS. The ATSS sounds a lot like the IES. Because of the overlap with the IES, maybe the IES should be renamed.

ORNL RESPONSE: There is no reason why there should not be a healthy synergism between the ATSS and the IES. However, these groups do have different responsibilities. The IES, for instance, has the staff to prototype software innovations. The ATSS will not have permanent staff to work on such projects. The ATSS will have responsibility for technology issues broader than software innovation and for ensuring technology transfer into and throughout the Bureau. The IES is responsible for transferring its products to designated users. The ATSS will provide analytical support to the Technology Forum and to the Executive Staff on technology issues. Thus, the ATSS will need technical people trained in the art of policy analysis. The IES employs highly trained computer scientists. The ATSS will have some resources to fund innovation and could fund the IES. However, these funds should be available to interested people throughout the Bureau. In our view, there are enough differences between the ATSS and the IES that they should be separate entities. We recommend against consolidating the ATSS, the IES, and parts 
of other Bureau activities as this is not in the best interests of decentralizing Bureau technological skills.

COMMENTS: Having the ATSS report to the Bureau's Deputy Director will make it out of touch with the Bureau's day-to-day operations.

ORNL RESPONSE: The only place in the Bureau where the ATSS would have the opportunity, admittedly through hard work, to understand the technology needs of the entire Bureau is in a box separate from the day-to-day operations of any particular part of the Bureau. Because some of the Technology Forum requests for policy studies may involve the ADP Services area, it is best that the ATSS not report to Managment Services. These constraints limit placement of the ATSS in the organization to having it report to the Deputy Director. Again, though, the placement of the ATSS may be reconsidered in light of other organizational changes.

COMMENT: Because the ATSS has some relationship to Information Resouce Management, it should report to the head of Management Services.

ORNL RESPONSE: As explained earlier, we believe that technology issues are broader than IRM issues.

COMMENT: The ATSS should look for revolutionary ways to apply technology to Bureau activities.

ORNL RESPONSE: We agree.

COMMENT: The ATSS should not be involved in funding innovation projects.

ORNL RESPONSE: We disagree. The ATSS will have some funds for exploring high-risk, high pay-off ideas. It will not fund many nor large projects; just proof-of-concpt projects. This responsibility is appropriate for the ATSS. 
COMMENTS: The ATSS will have too much work given its small staff. Temporary stafi will not work because divisions will not give up its best and brightest. The staff needs to be larger and permanent.

ORNL RESPONSE: These comments have merit and should be considered.

\section{A.8 MULITPLE RECOMMENDATION COMMENTS}

COMMENT: Taken together, the recommendations add management layers.

ORNL RESPONSE: The last thing that people in the Bureau want is more management. However, everybody is interested in performing their jobs better. We believe that the recommendations are sensitive to these two concerns. Synergism between the Technology Forum, the informal innovation process, and the Advanced Technology Studies Staff will result in more efficient discussions and communications about technology. There will be less time wasted in meetings that represent ad hoc attempts to solve technology problems and we hope decisions will be made faster. Also, strictly speaking, there are no additional management layers. The Technology Forum will be a focal point for discussions that are now more or less ad hoc. The Technology Review Committee and the Technology Gurus are not management related. The Process for Innovation is informal, not manadated. The ATSS does not tepresent new managment. In fact, one of its responsibilities is to reduce bureaucratic problems. Thus, we believe that the recommendations will not create additional management burdens.

COMMENTS: It is better to have a Chief Technology Offic:- (CTO) than the Technology Forum and the Advanced Technology Studies Staff; people can get things done better than committees. A CTO is a bad idea, a step backwards; it is not in a decentralized mode. 
ORNL RESPONSE: The Bureau culture would not, in our opinion, tolerate a Chief' Techology Officer. The Bureau operates by consensus management. A change from this mode of operation would cost the Bureau many key staff. Everyone wants to feel that their opinion is important and to be listened to because they believe what they are doing is important. The Technology Forum and the ATSS are designed with the Bureau's culture in mind.

\section{A.9 NEW RECOMMENDATIONS}

COMMENT: A reward system for creativity should be used to encourage innovation.

ORNL RESPONSE: This is a good idea in theory. Some thought is needed on how to implement it.

\section{A.10 OBSERVATIONS AND IMPLEMENTATION RECOMMENDATIONS}

We are pleased that so many people took the time to provide comments, although we wish more had responded. As expected, reactions to the recommendations ranged from strongly positive to strongly negative, with most people supportive but near the middle. As with any new ideas and innovations, time is needed for their full evaluation and implementation. A year or two must pass before one will be able to judge the ultimate value of this report to the Census Bureau.

None of the comments persuaded us to change any of the recommendations presented in Sect. 4.0. We believe that the recommendations present a good point of departure for discussion, at the very least. Preparing our responses to the comments actually increased our confidence in the soundness and value of the recommendations.

Several reviewers were interested in how the recommendations should be implemented. One reviewer stated that a small group of senior managers be appointed to study the 
recommendations and then report their findings to the Executive Staff. This seems a reasonable approach.

We recommend that initial discussions focus on establishing the Technology Forum. The Forum is the key recommendation and would have the most impact. Also, the Forum could then discuss the other four recommendations. Establishing the Forum would be an Executive Stalf decision, maybe based on the findings of the small study group.

The Technology Review Committee would not be difficult to implement, if all the guidelines for such committees are followed. The Technology Gurus would be easy to implement, too. Maybe one or two could be appointed on a trial basis. The Innovation Process needs no implementation; just pass around the figure for people to refer to if they have innovation impulses.

The ATSS, in theory, would not be hard to implement if funding were available to set it up. However, the cuntroversy indicated by the comments about the ATSS indicates some time may be needed to reach a consensus. The Forum would be an excellent place to hold discussions on the ATSS. 

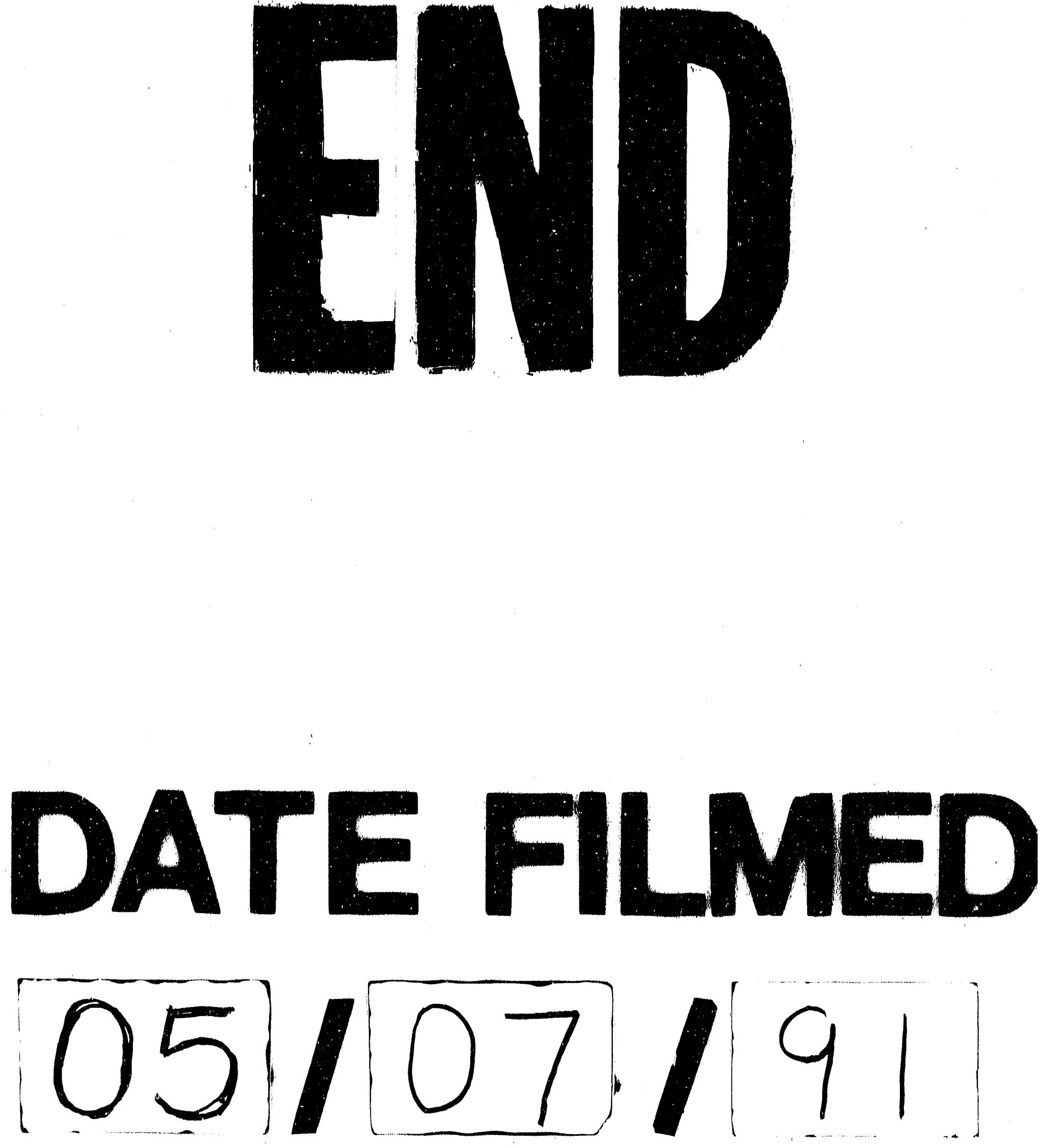
